\title{
VISION
}

for the

\section{Future of the US National Strong-Motion Program}

\author{
Prepared by
}

\section{The Committee for the Future of the US National Strong-Motion Program}

\author{
R. Borcherdt, Chairman \\ USGS Members \\ H. Benz, M. Celebi, A. Frankel, W. Joyner, E.V. Leyendecker, D. Oppenheimer, R. Porcella, C. \\ Stephens, D. Wald \\ External Advisory Panel Members \\ B. Bolt, C.B. Crouse, G. Hart, K. Jacob, T. Shakal, C. Stepp \\ U.S. Geological Survey Report \\ Open-File Report Number 97 - 530 B \\ October 4, 1997
}

This report is preliminary and has not been reviewed for conformity with U.S. Geological Survey editorial standards or with the North American Stratigraphic Code. Any use of trade, product, or firm names is for descriptive purposes only and does not imply endorsement by the U. S. Government. 


\section{TABLE OF CONTENTS}

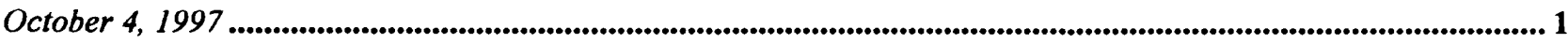

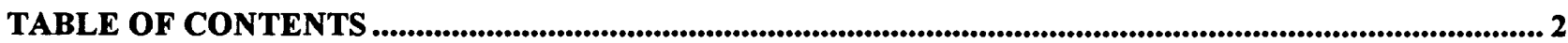

VISION SUMMARY

I -- Contribution of Strong-Motion MEASUREMENT to EARTHQuake HaZard Mitigation and Loss

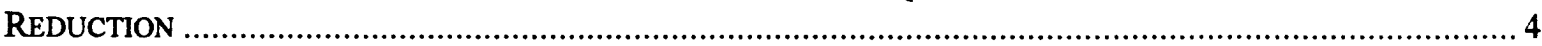

How significant is the earthquake threat to public safety? .................................................................. 4

Why are strong-motion recordings critical for significant improvements in public safety?................... 4

What are strong-motion recordings? ........................................................................................... 4

Why is the present set of US strong-motion recordings inadequate? .............................................. 5

Why is a thorough set of strong-motion recordings of the next damaging earthquake an urgent national

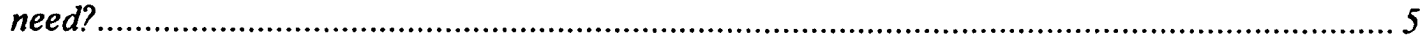

What resources are required to provide an adequate set of strong-motion recordings of the next major earthquake in the coterminous United States? ...................................................................... 5

What resources are required to record a specific earthquake in one of the areas with high population exposure to damaging ground motions? .............................................................................. 5

What proportion of strong-motion stations should be equipped with real time telecommunication for purposes of disaster assessment and emergency response? ....................................................... 6

II -- RELATIONSHIP OF THE NSMP TO OTHER STRONG-MOTION PROGRAMS AND EHRP SUPPORTED NETWORKS INCLUDNG THE REGIONAL NETWORKS, THE US NATIONAL SEISMOGRAPH NETWORK, AND THE EVOLVNG

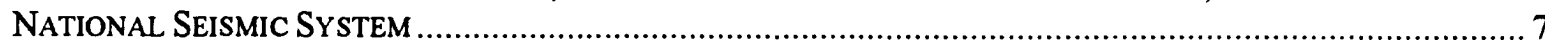

Why are most national and regional seismic-network stations not appropriate for strong-motion measurement and vice-versa?........................................................................................... 7

Why do network and strong-motion stations require different types of modern instrumentation? ......... 7

How should the NSMP be interfaced and integrated with other EHRP supported networks? .............. 7

How should the NSMP be interfaced and integrated with other strong-motion programs?................ 8

What opportunities exist to support NSMP with non-USGS funding including sales of NSMP products?

III -- VISION FOR THE ROLE AND FUNCTION OF THE NATIONAL STRONG-MOTION PROGRAM (NSMP) OPERATED

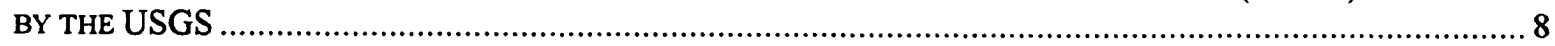

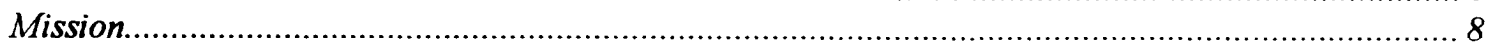

What is the proper role and function of the NSMP within the EHRP and the Earthquake Engineering

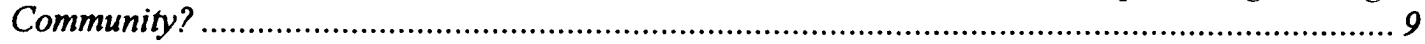

What are specific activities and functions of the NSMP that should be continued under the EHRP?.... 9

What is the appropriate role of the NSMP in efforts for near-real time disaster assessment and emergency response? .......................................................................................................... 11

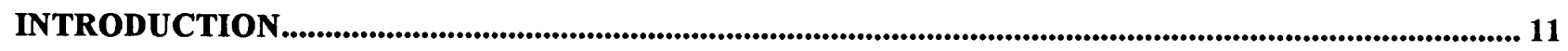

I - STRONG-MOTION RECORDINGS, THE BASIS FOR PUBLIC EARTHQUAKE SAFETY ............... 13

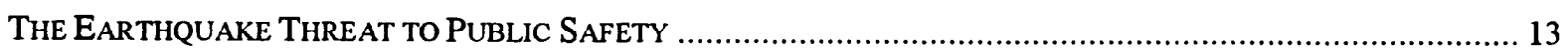

IMPORTANCE OF STRONG-MOTION RECORDINGS IN REDUCTION OF EARTHQUAKE HAZARDS AND LOSSES ..... 14

SCARCITY AND NATIONAL URGENCY FOR STRONG-MOTION RECORDINGS ............................................ 14

SPECIAL PROBLEMS ASSOCIATED WITH ACQUISITION AND DISSEMINATION OF STRONG-MOTION RECORDINGS

STRONG-MOTION INSTRUMENTATION NEEDED TO IMPROVE PUBLIC SAFETY …............................................ 15

Strong-Motion Instrumentation Needs -- As Estimated on a National Scale .................................. 15

Strong-Motion Instrumentation Needs -- As Estimated in Detail on a Regional Scale........................ 18

II - REGIONAL AND NATIONAL NETWORK EARTHQUAKE RECORDING EFFORTS ....................... 23

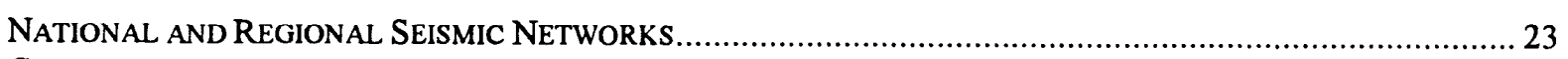

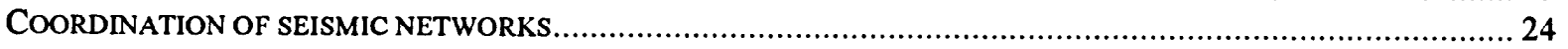


III - THE NATIONAL STRONG-MOTION PROGRAM - A NATIONAL PROGRAM TO ACQUIRE AND MAINTAIN AN ON-SCALE MEASUREMENT STANDARD AND DATABASE FOR PUBLIC

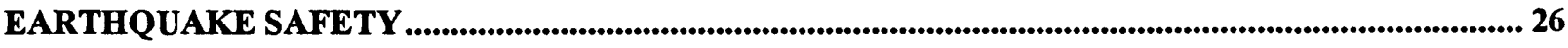

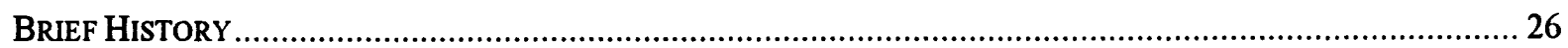

CONTRIBUTIONS OF THE STRONG-MOTION PROGRAM TO THE ASSESSMENT OF EARTHQUAKE HAZARDS AND

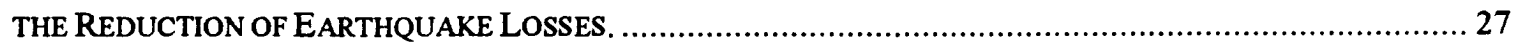

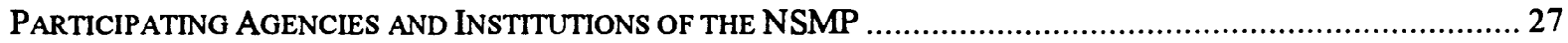

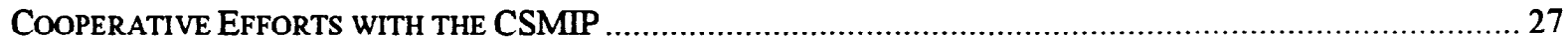

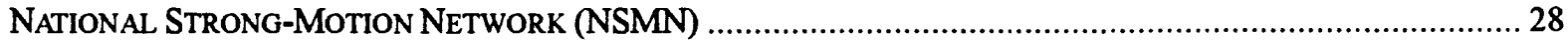

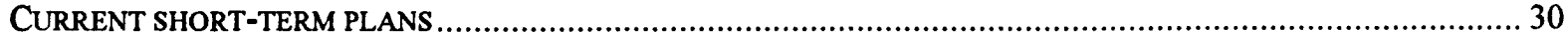

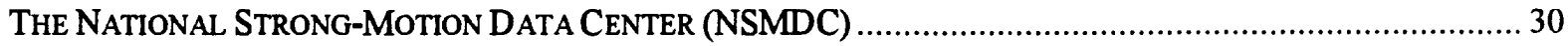

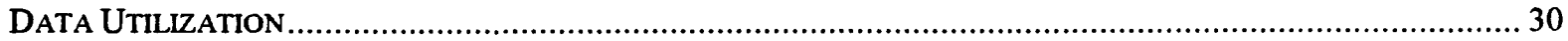

STRONG GROUND-MOTION MEASUREMENT NEEDS FOR EARLY WARNING............................................. 30

GROUND-MOTION MEASUREMENT NEEDS FOR MAPS OF SHAKING ..................................................... 31

MEASUREMENT NEEDS FOR STRUCTURAL ENGINEERING RESEARCH .................................................. 32

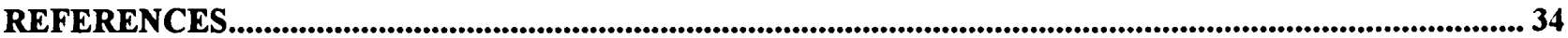




\section{VISION SUMMARY}

This document provides the requested vision for the future of the National Strong-Motion Program operated by the US Geological Survey. Options for operation of the program are presented in a companion document.

Each of the three major charges of the EHRP, program council pertaining to the vision document is addressed here. The "Vision Summary" through a series of answers to specific questions is intended to provide a complete synopsis of the committees response to program council charges. The Vision for the Future of the NSMP is presented as section III of the Summary.

Analysis and detailed discussion supporting the answers in the summary are presented as sections organized according to the charges of the program council. The mission for the program is adopted from that developed at the national workshop entitled "Research Needs for Strong Motion Data to Support Earthquake Engineering" sponsored by the National Science Foundation.

\section{I - CONTRIBUTION OF STRONG-MOTION MEASUREMENT TO EARTHQUAKE HAZARD MITIGATION AND LOSS REDUCTION}

How significant is the earthquake threat to public safety?

- Staggering losses from recent earthquakes impacting Northridge, California (\$15 to $\$ 25$ billion, 64 lives) and Kobe, Japan ( $>\$ 100$ billion and 5500 lives) clearly demonstrate the potential impact of moderate earthquakes on modern urbanized societies.

- Dramatic increases in urbanization based on inadequate safety standards implies that costs in lives and property from a future major earthquake in the United States could exceed $\$ 200$ billion dollars, cause several thousand deaths, and significantly impact the global economy.

Why are strong-motion recordings critical for significant improvements in public safety?

- Public safety requires that man-made structures resist strong, earthquake-induced shaking.

- Strong-motion recordings are the quantitative in-situ measurement of shaking and the resultant dynamic performance of structures needed to build and strengthen the built environment to resist future earthquakes.

- Strong-motion recordings are the basis for all current earthquake-resistant design, construction, and retrofit codes and practice.

- Strong-motion recordings are the basis for a significant proportion of the research products produced by the USGS as specified in the FY 1997 EHRP 5-year plan.

- Strong-motion recordings are necessary for real-time damage assessment and emergency response in densely urbanized areas as both efforts require dense sets of on-scale measurements of damaging levels of shaking on and near structures in earthquake stricken areas.

- The present scarcity of quantitative measurements of ground shaking and its damaging effects on the built environment is a major obstacle to reducing future losses of life and property to manageable levels.

What are strong-motion recordings?

- Strong-motion recordings are on-scale recordings of the main damaging earthquake at locations of most significance for public earthquake safety.

- Strong-motion recordings are recordings of the main shock, often on or near structures in densely urbanized environments, within $20 \mathrm{~km}$ of the earthquake-rupture zone for sites on rock and within about $100 \mathrm{~km}$ for sites on soft soils. Recordings of motions at levels sufficient to cause damage at 
sites at greater distances also are of interest for earthquake engineering in areas likely to be affected by large subduction zone earthquakes or in areas with exceptionally low attenuation rates.

Why is the present set of US strong-motion recordings inadequate?

- No recordings of any major $\left(M_{w}>7.5\right)$ US earthquake at locations experiencing damaging levels of shaking,

- No recordings of any high-rise, steel-moment frame building within $20 \mathrm{~km}$ of a moderate to large $\left(M_{w}>6.5\right)$ US earthquake,

- No recordings of any critical lifeline at damaging levels of motion, such as the six major bridges crossing the San Francisco Bay that are being presently retrofitted, based on as yet undocumented levels of ground shaking,

- Few $(<10)$ recordings of the dynamic response of soft soils, yet billions of dollars of bridges, buildings, pipelines, and highways are being built on such deposits each year,

- Few $(<10)$ recordings of large sudden coherent pulses of motion ("fault fling" or "killer pulses") that occur near the fault rupture and are expected to cause catastrophic losses for cites such as Hayward, Oakland and Berkeley, CA,

- Few or no recordings of most modern structures in their in-situ environment to actual damaging levels of earthquake loading,

Why is a thorough set of strong-motion recordings of the next damaging earthquake an urgent national need?

- Billions of dollars are being expended each year to build and strengthen the built environment based in many cases on as yet undocumented strong ground shaking and structural performance levels,

- If thorough sets of strong-motion recordings of the next major earthquake are not obtained on and near structures in the stricken areas, then another important infrequent opportunity will be missed,

- Present expenditures based on a totally inadequate database will continue and the catastrophic costs of future earthquakes will increase exponentially with time as urbanization increases.

- The high likelihood for a major damaging earthquake to strike areas such as the San Francisco Bay region within the next five years, implies an urgent effort is required to acquire and install the necessary resources to prevent another major missed opportunity.

What resources are required to provide an adequate set of strong-motion recordings of the next major earthquake in the coterminous United States?

- Recent consensus of a national workshop (Stepp, 1997) implies a dramatic increase in resources (funding and people) is needed to ensure that critically needed instrumentation (20,000 stations) is operational by the year 2005.

- Estimates derived on the basis of recent National Seismic Hazard Maps (Frankel, et al., 1996) and estimates of population exposure imply that instrumentation at about 20,000 sites is needed with 7,000 for ground-motion, 7,000 for buildings, 3,000 for lifelines, such as bridges and pipelines, and 3,000 for critical facilities necessary for emergency response and near-real time disaster assessment.

What resources are required to record a specific earthquake in one of the areas with high population exposure to damaging ground motions?

- Estimates of the density and location of strong-motion stations needed to record a specific earthquake can be developed for each urban area using modern GIS technology, regional 
estimates of ground shaking, inventories of the built environment, and modern methods to predict resultant earthquake losses.

- Application of the procedures to the San Francisco Bay Region for a repeat of the 1906 earthquake (Mw 7.7) provides significant insight for strong-motion planning purposes.

- Estimated losses for a repeat of the 1906 earthquake are expected to exceed $\$ 200$ billion with more than 5000 deaths (RMS, inc., 1995).

- 140 - 180 ground-motion station are needed in the city of San Francisco with a spacing of no more than a few blocks in the heavily impacted financial district.

- Superposition of the built environment on predicted ground shaking maps shows that in the southern San Francisco Bay region $45 \%$ of the 1079 bridges, $69 \%$ of the 16 airports, $22 \%$ of the 233 hazardous material sites, $48 \%$ of the 99 medical facilities, and $48 \%$ of the 801 schools are located in areas expected to experience damaging levels of shaking that exceed $0.6 \mathrm{~g}$ in spectral response acceleration at 1.0 second.

- Superposition of the transportation facilities on a site class map based on the 1994 Recommend Building Code provisions shows that $69 \%$ of the bridges, $57 \%$ of the highways, and $100 \%$ of the railways are located on either stiff clays and sandy soils or on soft clays with a high to very high amplification capability and moderate-to-high liquefaction susceptibility.

- The large percentages of important structures $(\sim 990)$ and buildings $(>3000)$ located in areas of potentially damaging ground shaking suggest that more than 4000 sites in the SF Bay region need to be considered for instrumentation.

- If only 10 percent of especially vulnerable structures in the southern SF bay region are instrumented, then at least 400 instrumentation arrays on and near structures are needed.

- Instrumentation estimates show that the present level of strong-motion instrumentation in the densely urbanized areas of the San Francisco Bay Region is woefully inadequate to document the ground shaking and the resultant seismic performance of the built environment to a repeat of the 1906 earthquake.

What proportion of strong-motion stations should be equipped with real time telecommunication for purposes of disaster assessment and emergency response?

- Modern instrumentation with telecommunication capabilities permits areas of strongest shaking and the performance of structures to be quickly assessed. Instruments on structures such as major buildings, hospitals, schools, bridges, freeway overpasses, dams etc. permit rapid assessment of probable Damage State, efficient dispatch and routing of emergency response resources, and efficient prevention of additional disaster. Several important examples illustrating the application of modern technology to Disaster Reduction now exist in Japan.

- Preliminary estimates on the basis of estimated shaking levels suggest that some $50-85 \%$ of the strong-motion instrumentation installed for ground-motion measurement purposes in cells of highest population exposure should be equipped with near-real time communication capabilities for at least some channels.

- Considerations based on the geographic distribution of the built environment for the southern San Francisco suggest some 25 to 50 percent of instrumented structures should also be equipped with telecommunication for a few data channels to assess the damage state of the structures in nearreal time. 
II - RELATIONSHIP OF THE NSMP TO OTHER STRONG-MOTION PROGRAMS AND EHRP SUPPORTED NETWORKS INCLUDING THE REGIONAL NETWORKS, THE US NATIONAL SEISMOGRAPH NETWORK, AND THE EVOLVING NATIONAL SEISMIC SYSTEM

Why are most national and regional seismic-network stations not appropriate for strong-motion measurement and vice-versa?

- The national network and the regional networks operated by universities and the USGS with guidance of Incorporated Research Institutes for Seismology (IRIS) and the Council for the National Seismic System (CNSS) are comprised of 2115 stations (Malone, pers. commun., 1997) of which 1772 are short-period regional stations, 183 are broadband stations, and 160 are termed digital strong-motion stations.

- The necessity to locate national and regional network stations in areas appropriate for monitoring seismicity using weak motions requires that they be located in seismically quite areas on firm-tohard rock, away from cultural noise sources and densely urbanized areas, and at distances often much greater than $20 \mathrm{~km}$ from potentially damaging earthquake-rupture zones. With the exception of a few stations these objectives preclude the use of most network station locations as strong-motion stations.

- Superposition of network stations on maps showing average annual exceedance rates for $0.1 \mathrm{~g}$ and average annual population exposure to $0.1 \mathrm{~g}$ shows that only a few percent of these stations are in locations expected to experience strong-motions in urban areas during the next 100 years.

- Superposition of network stations in the San Francisco Bay region shows that one station at the Presido in San Francisco and 12 other stations in the hills away from the urbanized flatlands of the Bay regions are located so as to experience damaging shaking levels greater than $0.1 \mathrm{~g}$ from a repeat of the 1906 earthquake. Recordings at these sites would be of interest for studying the nature of near-source seismic radiation, but not for ground motion measurement for purposes of damage assessment or performance of the built environment.

- Most strong-motion stations urgently needed to monitor the built environment and needed for nearreal time damage assessment must be located near or on man-made structures in areas underlain by soils with high cultural background noise levels. These locations are not appropriate for network stations required to observe weak motions for seismicity studies.

Why do network and strong-motion stations require different types of modern instrumentation?

- Seismicity-monitoring equipment needs to be highly sensitive to record weak motions using continuous telemetry. As most of these stations are not expected to experience damaging levels of motion within the next 100 years they need not install accelerometers nor on-site recording capabilities.

- Strong-motion stations must record and survive acceleration levels up to $2 \mathrm{~g}$ on site. Such sites in noisy urban environments can not use sensitive sensors, but require accelerometers and on-site recording. Real-time telemetry is only needed for data channels used for disaster assessment and emergency response purposes and would be prohibitively expensive if employed to record the several thousands of channels of data required to monitor presently instrumented buildings.

- Necessity to minimize instrumentation costs and the fact that most sites serve either a weak- or strong-motion monitoring purpose, but not both, requires that modern instrumentation with sensors, recording media, and telemetry requirements best suited for each purpose be installed at each type of site.

How should the NSMP be interfaced and integrated with other EHRP supported networks?

- Differences in station locations, instrumentation performance and maintenance requirements and data recovery and processing requirements for weak and strong motion recordings suggests that 
separate maintenance and data processing efforts as they have evolved historically are cost effective and should be maintained.

- Establishment of a true "Virtual Data Center" with data from each of the recording programs readily available in a variety of formats via inquires to the NSMDC, the IRIS data center, or any regional-network center provides very effective integration of the programs. This method of integrating the programs, as exemplified by TRI-NET, allows each program to best serve its separate user communities while utilizing and sharing resources and data wherever possibie.

How should the NSMP be interfaced and integrated with other strong-motion programs?

- The NSMP has a long-standing tradition of interfacing, integrating, and cooperating with all strong-motion monitoring efforts in the United States.

- The NSMP presently has formal strong-motion station operational responsibility in cooperation with 15 other federal, state and local agencies and 25-30 private owners. Formal financial reimbursement arrangements for operation and maintenance of these stations help support the NSMP.

- The NSMP works in close cooperation with the only other major strong-motion program in the US, namely the California Strong-Motion Instrumentation Program (CSMIP), which it initially helped establish.

- The need for instrumentation in both state and federal facilities, the urgent need for dramatic increases in strong-motion instrumentation, and separate mandates for measurement of the main earthquake at separate locations of significance for society requires that both programs continue to operate cooperatively in the State of California. The strong-motion measurement-needs of society can not be met if either program were to discontinue operations in California.

- The NSMP and the CSMIP should continue to work cooperatively in establishing and maintaining standards for instrumentation and data processing appropriate for the earthquake engineering industry and solution of critical research problems.

What opportunities exist to support NSMP with non-USGS funding including sales of NSMP products?

- The cooperative arrangements established with 15 other agencies and 20-25 owners have proven to be a very effective means of sharing costs of instrumentation and long-term maintenance.

- Attempts to recover costs through charges for data have been shown to be inappropriate and ineffective.

III - VISION FOR THE ROLE AND FUNCTION OF THE NATIONAL STRONG-MOTION PROGRAM (NSMP) OPERATED BY THE USGS

\section{Mission}

The Mission of the US National Strong-Motion Program is to increase public safety by providing earthquake strong-motion measurements on and near man-made structures to the earthquake engineering community, the scientific community, public agencies, industry, media, and other users for purposes of:

- Improving engineering evaluations and design methods for facilities and systems,

- Providing timely information for post-earthquake alerting, damage assessment, and emergency response action,

- Contributing to a greater understanding of the mechanics of earthquake generation and groundmotion characteristics. 
What is the proper role and function of the NSMP within the EHRP and the Earthquake Engineering Community?

- The National Strong-Motion Program (NSMP) as mandated by the Earthquake Hazard Reduction Act of 1978 should enhance and continue to strive to significantly improve public earthquake safety through the fulfillment of it's national responsibility to record the main earthquake at locations of most significance for public safety.

- The NSMP should continue to concentrate on the problem of recording each large and damaging earthquake in the United States on and near man-made structures throughout damaged urban areas. No other seismic monitoring program operated by the USGS is focussed on this urgent and critical national need.

- The NSMP should continue to coordinate federal efforts, help integrate state and local efforts and provide national leadership to acquire, process, and disseminate strong-motion recordings according to a standard that can be used by the earthquake resistant design and retrofit industry as well as the research community for solution of specific research issues.

- The NSMP should enhance and continue to facilitate, coordinate, and integrate through existing partnerships efforts of the following agencies in the United States: Army Corps of Engineers, California Department of Water Resources, Department of Veterans Affairs, General Services Administration, Hawaii State Civil Defense, Metropolitan Water District of Southern California, Oregon Department of Transportation, University of Puerto Rico, U.S. Department of Energy, Utah Geological Survey, Washington, City of Aberdeen, Washington, Tacoma Public Utilities, Washington Dept. of Naturai Resources, Washington Department of Transportation, Property Owner (Code mandated), Universities, and others. It should continue cooperative efforts with the other significant strong-motion programs, namely that of the California Division of Mines and Geology.

- The NSMP should support and be an integral part of a new National Consortium of Organizations for Strong-Motion Observational Systems (COSMOS; Stepp, 1997) as it develops to advance the measurement of strong motion for public earthquake safety.

- The NSMP should strongly support COSMOS objectives to share, leverage and develop the dramatic increase in resources needed to meet critical on-scale measurement needs for damaging earthquakes at locations of significance for public earthquake safety by the year 2005 (Stepp, 1997). Costs of instrumentation range between $\$ 200-500$ million.

- The NSMP should continue to cooperate and support the efforts of both the engineering and seismology communities. It needs to support efforts of several committees, including: Committee for the Advancement of Strong-Motion Programs, appropriate committees of the National Academies of Science and Engineering, the Strong-Motion Committee of the Earthquake Engineering Research Institute, the Seismology Committee of the Structural Engineers Association of California, the California Strong-Motion Instrumentation Program of California Division of Mines and Geology, TRI-Net, the Council for the National Seismic System, among others.

- The NSMP should establish an Advisory Board to assist the USGS in the planning and implementation of the NSMP as recommended by the EHRP five year review panel. It should model the concept after that of the State of California Strong Motion Instrumentation Program (CSMIP) whose advisory panels have proved very successful in meeting public safety needs.

What are specific activities and functions of the NSMP that should be continued under the EHRP?

- Urgency and national need for strong-motion recordings of each damaging earthquake argues strongly for restoration and expansion of NSMP funding and staff levels as quickly as EHRP resources permit. 
- Major efforts are needed to increase resources devoted to recording the main shock at locations of most significance for society as quickly as possible. An EHRP monitoring program that cannot record the main earthquake at locations of importance needed for earthquake loss reduction is not an adequate earthquake measurement program.

- The NSMP should continue to pursue a well integrated set of specific objectives as specified in the FY 1998 Project proposal for the NSMP concerning data acquisition, data management and data utilization as best it can with present resources;

\section{Data Acquisition -}

- The NSMP should maintain and enhance the present National Strong-Motion Network of 850 accelerographs at 540 stations in 33 states and Puerto Rico in cooperation with aforementioned agencies.

- The NSMP should enhance and maintain integrated borehole, structural response, and portable strong-motion arrays in cooperation with other USGS networks.

- The NSMP should continue to vigorously assume its responsibility for instrumentation of federal buildings as described by Celebi and Nishenko (1997).

- The NSMP should establish an aggressive schedule for replacing analog strong-motion instruments with digital accelerographs.

- The NSMP should establish an aggressive schedule for implementing modern telecommunications for rapid data retrieval and interpretation for near-real time damage assessment and emergency response on and near the built environment.

- The NSMP should enhance and maintain a national database of geologic and geotechnical site characteristics for each strong-motion instrumentation site.

- The NSMP should continue to pursue an aggressive program to develop resources to instrument man-made structures in cooperative partnerships with other agencies.

Data Management -

- The NSMP should enhance and continue to operate the National Strong-Motion Data Center (NSMDC) in order to maintain a central national data base at a consistent standard for all of the earthquake-resistant design, retrofit, and construction industry and numerous research and public response communities.

- Major activities of the NSMDC should include: 1) digitize, process, archive and disseminate backlog of analog strong-motion records, 2) implement modern NSMDC data base for rapid data retrieval and dissemination via Internet, ftp sites, CD-Rom etc., 3) develop and implement hardware and software for rapid incorporation of near-real time strong-motion data into NSMDC data base for rapid dissemination via NSMP web site, 4) manage the playback and archival of large volumes of borehole array and post-earthquake and portable-array digital recordings for dissemination via the Internet to the various practicing engineering and research communities.

\section{Data Utilization --}

- The NSMP should conduct associated data utilization and research program based on analysis and interpretation of strong-motion recordings. This portion of the program should emphasize critical problems pertaining to the evaluation and prediction of damaging levels of earthquake ground shaking and structural response for purposes of improving building codes and resolving important research issues concerning the physics of seismogenic rupture, propagation of seismic radiation, and their effects on man-made structures

- The NSMP should maintain and enhance efforts to:

1. Predict strong motion as a function of earthquake magnitude, distance, and geologic conditions,

2. Develop and improve geologic and geotechnical data base for strong-motion stations 
3. Conduct empirical and theoretical studies of soil response for NEHRP and UBC sitespecific, building code provisions and CA law AB-3897,

4. Conduct studies of structural response and soil-structure interaction for improvements in NEHRP/UBC building codes,

5. Continue to support interpretations of strong-motion recordings necessary for most elements of the 1998 USGS EHR Program Prospectus including: National Seismic Hazard Maps, Urban Hazard maps, Seismic Monitoring of Main Shock in Urban Areas, Physics of Earthquake Rupture, Strong Ground Shaking Characteristics of Earthquake Sources, Site Specific Hazard, Ground Failure, and Response of Structures each of which is necessary for improved public earthquake safety through improved building and bridge codes,

What is the appropriate role of the NSMP in efforts for near-real time disaster assessment and emergency response?

- Near real-time disaster assessments and emergency response require strong-motion measurements of shaking on and near critical lifelines, hospitals, emergency response facilities and other manmade structures thoroughout stricken, urban areas.

- Strong-motion measurements in urbanized areas for disaster assessment and emergency response purposes must necessarily be an integral part of NSMP activities.

- The NSMP should help develop program implementation plans in cooperation with other interested scientific and engineering professionals in order that resultant recordings best meet the needs of the practicing engineering and emergency response community.

- The NSMP should help integrate implementation efforts with on-going strong-motion monitoring efforts of other federal, state, local, and private agencies responsible for buildings, bridges, highways and other man-made facilities in order to maximize cost effectiveness.

- The NSMP should contribute to the development of a near-real time virtual database for use by a large number of users for a variety of purposes,

- The NSMP should help develop detailed siting plans in urban areas, help establish instrumentation standards, and develop maintenance plans required to keep the instrumentation operational for decades often required to obtain strong-motion recordings.

\section{INTRODUCTION}

Recent earthquakes dramatically demonstrate that future earthquakes could cause tremendous loss of life and property. These losses result from damage and collapse of man-made structures caused mostly by strong earthquake induced shaking. Consequently, mitigation of earthquake loss of life and property requires that the nature of earthquake shaking that can be expected in various locations be well understood and that structures be built and strengenthened to resist it. Such understanding must necessarily be based on thorough sets of recordings of past earthquakes. Presently, the scarcity of recordings of strong, damaging earthquake-induced shaking is a major obstacle to reducing future losses of life and property to manageable levels.

Two types of efforts are presently expended to record earthquake shaking. The first type of recording may be termed "weak-motion". This type is conducted for purposes of monitoring seismicity on local, regional, national, and global scales. It focusses on recording the shaking from all events ranging from very small local events to distant large events that radiate seismic waves of sufficient amplitude to be detectable above seismic background noise levels. This type of effort is manifest in the NEHRP as regional and national seismic networks. Stations for the networks must necessarily be located in quite seismic environments, usually on firm-to-hard rock in areas away cultural noise sources associated with man-made structures. They are usually distributed over broad geographical regions of heightened seismicity or across the nation for contributions to global seismicity studies. These stations require 
especially sensitive sensors and continuous telemetry in order that earthquake locations and magnitudes can be rapidly inferred at a central data collection center. Most of these network stations have not and are not expected to experience damaging, strong ground-motion levels exceeding, for example, $0.2 \mathrm{~g}$.

The second type of recording, termed "strong-motion" , refers to recordings of the main earthquake at locations sufficiently close to the source that resultant shaking levels are of sufficient amplitude to cause damage. These recordings are required to understand strong ground shaking and its effects on the built environment. These locations are generally within $20 \mathrm{~km}$ of the source for rock sites and less than 100 $\mathrm{km}$ from the causative rupture zone for sites on soft soil. Recording locations on and near man-made structures throughout stricken urban areas are of special significance and importance. This type of effort is manifest in NEHRP as the National Strong-Motion Program. Stations for this type of recording require a different type of sensor known as an accelerometer. The sensors must be capable of sensing and withstanding motions as severe as $2 \mathrm{~g}$, but they need not, and no sensor can, sense motions ranging from this amplitude down to levels which permit quiet seismic noise levels to be well resolved. Because of vulnerabilities of telemetry systems, stations designed to record the main shock in areas of damaging shaking must record the data on site which in turn requires different procedures for data collection and dissemination.

Historically, different objectives, different types of required recording sites, different instrumentation requirements, and different primary user groups have led to separate projects within the NEHRP for operation and maintenance of "weak-" and "strong-"motion networks. Recent planning for the future of the EHRP as conducted in part by the USGS and mananged under the auspices of the program council require that these differences be reevaluated in light of modern instrumentation developments to determine if more cost effective prcedures might be available.

Results derived herein based on new national seismic hazard maps and GIS technology show that differences in "weak" and "strong" motion recording do indeed not only support the present distinctions in the operation of the programs, but require that these distinctions be respected in order that the important objectives of each type of recording be achievable. Unfortunately, historical evolution of the networks has led to an order of magnitude more USGS, NEHRP resources being devoted to "weak-motion" networks than "strong motion". This imbalance has arisen in part because small and distant large earthquakes are much more frequently experienced at a quiet site than are large damaging levels of motion in an urban environment. As a result, a preponderance of resources and research interests of geophysicists and seismologists have gravitatd toward instrument installations and studies based on "weak" motion data for which results can be derived in the short term. This unfortunate imbalance means unless significant new resources are deployed to record the main shock of the next damaging earthquake sequence at noisy locations on and near structures in the stricken urban areas, another important opportunity to to take a giant leap forward in reducing the catastrophic losses of future earthquakes is going to be missed.

This document through an extensive summary and detailed supporting discussion and analyses is intended to objectively examine the future role and importance of a national effort to record earthquake generated shaking. It focuses on the problem of quantitative measurement of the shaking generated by the main shock at locations throughout damaged urban areas, in order that shaking and its effects on man-made structures can be better understood and results used to significantly reduce losses of future earthquakes.

The executive summary is intended to be a complete synopsis. It summarizes information discussed and presented in more detail in each of the three subsequent sections of the report. The sections are organized to correspond to the major charges of the EHRP Program Council pertaining to: 1) the importance and contribution of NSMP (strong-motion measurement) to earthquake hazard mitigation and loss reduction, 2) the interface and intergration of NSMP efforts with other strong-motion programs, and other NEHRP supported networks, and 3) the future role and function of the NSMP. 
An extensive set of previous workshops and reports have documented the importance and need for strongmotion measurement in urban environments. A thorough review of these past assessments of need is provided by Nigbor (1997). Arranged in chronological sequence these previous reports are:

Earthquake Prediction and Hazard Mitigation Options for USGS and NSF Programs, (NewmarkStever Report, 1976),

On the development of strong-motion instrument networks in the United States, (Matthiesen, 1978),

Proceedings, Strong Motion Earthquake Measurement Arrays, (Iwan, 1978),

U.S. Strong-motion Programs, (Borcherdt and Matthiesen, 1980),

Proceedings, US National Workshop on Strong-Motion Earthquake Instrumentation, (Iwan, 1981),

National Planning Considerations for the Acquisition of Strong Ground-motion Data, (Borcherdt, et al., 1984),

National Plan to Record Earthquake Motions on the Ground and in Man-Made Structures, (Spudich et al.,, 1985),

Proceedings, Workshop on Research Needs for Strong-Motion Data to Support Earthquake Engineering, (Higgens, C.J. (ed), 1993),

Proceedings, Earthquake Engineering and Risk Recommendation Workshop for EHRP 5-Year Plan, (Borcherdt and Frankel, 1997),

Proceedings, Vision 2005: An Action Plan for Strong-motion Programs to Mitigate Earthquake Losses in Urbanized Areas, (Stepp, 1997).

These reports provide an important historical perspective on the need and importance of strongmotion data. This need as initially envisioned still remains with the impacts of recent earthquakes emphasizing that the need is ever increasing at a rate commensurate with urbanization.

\section{I -- STRONG-MOTION RECORDINGS, THE BASIS FOR PUBLIC EARTHQUAKE SAFETY}

\section{THE EARTHQUAKE THREAT TO PUBLIC SAFETY}

Staggering losses from recent earthquakes impacting Northridge, California ( $\$ 15$ to $\$ 25$ billion, 64 lives) and Kobe, Japan ( $>\$ 100$ billion and 5500 lives) clearly demonstrate the potential impact of moderate to large earthquakes on modern urbanized societies. If a major earthquake impacted some densely urbanized areas of the United States in the near future, life and economic losses are estimated to be least twice as large. If these same earthquakes were to impact the areas in thirty to fifty years without any dramatic changes in earthquake safety, losses could reach tens of trillions of dollars due to increased urbanization with inadequate safety standards. These tremendous potential losses with catastrophic and global consequences argue strongly for dramaticaily accelerated programs to improve public earthquake safety as quickly as resources permit.

Reduction of life and property losses to low and manageable levels requires significant improvements in both Hazard Mitigation and Emergency Response. Quantitative measurements of strong shaking referred to as "strong-motion recordings" are the critical and presently scarce element essential for significant progress in both areas. Modern technology offers important new opportunities to acquire these recordings. 


\section{IMPORTANCE OF STRONG-MOTION RECORDINGS IN REDUCTION OF EARTHQUAKE HAZARDS AND LOSSES}

Earthquake shaking is the basic cause of most earthquake loss. It causes the collapse of buildings, bridges, and other man-made structures, which in turn is the principal cause of loss of human life and property. Reduction of these potentially catastrophic losses requires that future and existing structures be constructed and strengthened to resist future strong, earthquake-induced shaking.

Strong-motion recordings of shaking are the basis for all earthquake resistant design, construction, and retrofit practices. They are the recordings of the mainshock at locations of special significance for improvement in public earthquake safety. They are the quantitative measurement standard on which allempirical estimates of shaking for US and international building codes are based. They are the measurements of strong shaking in locations of most significance for society, namely those locations of severe shaking in urban areas near and on buildings, hospitals, bridges, and other structures. They provide quantitative measurements of near-source seismic radiation.

Strong-motion recordings are the basis for a significant proportion of the research products produced by the USGS as specified in the FY 1997 EHRP 5-year plan. Strong-motion recordings are essential for the National Seismic Hazard Maps, Urban Hazard maps, Seismic Monitoring of Main Shock in Urban Areas, Physics of Earthquake Rupture, Strong Ground Shaking Characteristics of Earthquake Sources, Site Specific Hazard Assessment, Ground Failure, and Response of Structures.

Strong-motion recordings are the foundation of many measures to reduce losses in future earthquakes. They are the basis of attenuation relationships used to predict ground shaking for purposes of National Seismic Hazard Maps, site-specific design, and building codes.

For many issues important in earthquake safety, advances will not occur until a major earthquake provides new strong-motion data. It is vital that we plan wisely to obtain the greatest possible return from the strong-motion data collected in the next earthquake, so that society will not be forced to wait until the earthquake after that for the resolution of important safety issues.

Strong-motion recordings also are essential for real-time damage assessment and emergency response in densely urbanized areas. Both of these efforts require dense sets of on-scale measurements of damaging levels of shaking throughout stricken urbanized areas. Such measurements and in fact, any on-scale measurement of damaging shaking, using an established and calibrated instrument standard, is necessarily a "strong-motion" recording.

\section{SCARCITY AND NATIONAL URGENCY FOR STRONG-MOTION RECORDINGS}

The collection of strong-motion recordings in densely urbanized areas of significantly damaging earthquakes is very limited. For example, no recordings have been obtained of steel-moment frame buildings on soft soil within $20 \mathrm{~km}$ of a large magnitude $(>7)$ earthquake. No recordings have been obtained on critical lifelines, such as any of the six major bridges crossing the San Francisco Bay, yet billions of dollars are being expended to retrofit and rebuild these bridges to conform to higher, but as yet undocumented levels of ground shaking. No more than 10 recordings have been obtained at damaging levels of strong shaking on soft soils in the United States, yet hundreds of billions of dollars of buildings, airports, bridges, and lifelines are constructed near the margins of bays and rivers on such soils. No recordings have yet been obtained at near-source distances less than $20 \mathrm{~km}$ for any great or large earthquake in the United States, yet billions of dollars in property and thousands of people are located in regions expected to experience shaking from such an event in the future.

The critical lack of strong-motion information, the dramatic increase in urbanization with inadequate earthquake safety standards, and the tragic costs in life and property from recent moderate earthquakes indicate that urgent action is required at local, state, and national levels. A dramatic increase in instrumentation and associated maintenance resources is needed in order to ensure that the next tragic 
event is adequately recorded and the costs in life and property associated with subsequent events do not continue to have even greater global consequences.

\section{SPECIAL PROBLEMS ASSOCIATED WITH ACQUISITION AND DISSEMINATION OF STRONG- MOTION RECORDINGS}

The scarcity of strong motion recordings attest to the difficulty in acquiring these critically needed measurements of large earthquakes. Several factors contribute to this difficulty, including:

1) The infrequent occurrence of large and damaging earthquakes,

2) The need to maintain strong-motion measurement capabilities at sites for periods of time often longer than the life-time of the instrumentation and the employment intervals of the program staff (50-100 years),

3) The necessity of maintaining long-term personnel, funding, and administration resources and continuity necessary for installation and maintenance of the instrumentation and dissemination of resultant data,

4) The necessity of locating much of the instrumentation in urban areas on and near buildings, bridges, hospitals, and other man-made structures which are mostly locations that do not permit the stations to be used for other seismicity monitoring purposes,

5) The necessity to maintain instrumentation in a near 100 percent operational mode that can record and withstand shaking levels up to $2 \mathrm{~g}$, but may not provide data of much interest to scientists, engineers, researches and public policy officials in the intervening years,

6) The necessity to maintain instrumentation with on-site recording capability for long periods of time, perhaps decades, because of shaking vulnerabilities of telecommunication systems,

7) The need to maintain an instrumentation program whose first order user is the Earthquake Engineering Community comprised of a wide range of disciplines in an organization of predominately earth science disciplines.

\section{STRONG-MOTION INSTRUMENTATION NEEDED TO IMPROVE PUBLIC SAFETY}

An efficient and effective effort to thoroughly record the next major earthquake in the United States is clearly the highest priority earthquake measurement need of society. This effort needs to provide a thorough set of measurements at the locations of most significance for society, namely those locations near the source and near and on man-made structures throughout the heavily damaged areas. These strong-motion recordings need to be obtained at distances from the source less than about $20-25 \mathrm{~km}$ for sites on rock and less than $100 \mathrm{~km}$ for sites on soil. Measurements at these same distances and locations made in near-real time are required for near-real time disaster assessment and implementation of near-real time emergency response capabilities.

Estimates of the number and distribution of instrumentation needed to record the next earthquake are essential for future planning purposes. Estimates on a national scale provide an overall estimate of the general distribution and amount of instrumentation needed. Estimates on a regional scale provide insight as to specific locations and amounts of instrumentation needed on scales of a few city blocks. Estimates on a regional scale also to provide insight as to where instrumentation is needed for purposes of near-real time disaster assessment and emergency response.

\section{Strong-Motion Instrumentation Needs -- As Estimated on a National Scale}

The US national probabilistic seismic hazard maps (Frankel et al., 1997), recently prepared for the 1997 Recommended NEHRP Building Code Provisions provide a rigorous quantitative basis on which to develop a coordinated strong-motion measurement program. The maps together with information on 
population distribution provide the basic information needed to identify earthquake source zones and urbanized areas most likely to experience damaging levels of shaking. The maps prepared on a national scale with grid elements approximately $100 \mathrm{~km}^{2}$ in size permit general areas of highest priority to be identified for earthquake instrumentation.

More detailed maps showing areas of highest priority are required at a scale on the order of a few city blocks in order to identify final locations commensurate with locations of man -made structures. The maps provide a basis to evaluate the likelihood that stations presently installed will experience and record strong shaking within some reasonable future time period, such as 100 years.

A preliminary estimate of the instrumentation distribution needed to record ground shaking is summarized in Figure 1 and tabulated by state in Table 1 . These estimates are based on the annual exceedance rate for $0.1 \mathrm{~g}$ as calculated for the national seismic hazard maps (Frankel et al, 1997). They are specified on a $0.1 \times 0.1$ degree $\left(\sim 100 \mathrm{~km}^{2}\right)$ grid for the uniform ground condition firm to hard rock corresponding to NEHRP site class B (an in-depth treatment is provided by Borcherdt et al., 1997). The national distribution of population, specified on this same grid, was used to infer the corresponding annual population exposure to ground shaking level $0.1 \mathrm{~g}$ or higher. Grid cells with an annual exposed population of 3 people or less were considered of low priority and eliminated. The final estimates of ground shaking are specified for each cell as the maximum of the amount of instrumentation implied by the proportion of exposed population to $0.1 \mathrm{~g}$ and the amount per cell proportional to the annual exceedance probability for $0.1 \mathrm{~g}$.

With corrections to account for soft-soil amplification effects this procedure suggests a total number of ground-motion instrumentation stations for the United States of about 7500 (see Table 1). The map (Figure 1) and Table 1 indicate that the largest amount of instrumentation is needed in California and is concentrated in the areas of San Francisco and Los Angeles. Other concentrations of instrumentation are in the Portland, Oregon and Seattle-Tacoma, Washington areas; the central US (Saint Louis, Missouri; Memphis, Tennessee; Chicago, Illinois), and the eastern US (Philadelphia, Pennsylvania; New York, New York; Boston, Massachusetts), with small amounts of instrumentation in a number of other cities. Corresponding maps for the Alaska, Hawaii and Puerto Rico areas must await completion of seismic hazard maps. This estimate is shown to be a minimal estimate and that more dense instrumentation is needed in areas with high annual population exposure such as San Francisco (Borcherdt et al, 1997).

In addition to measurements of strong ground shaking, thorough and complete sets of measurements are needed on a wide variety of man-made structures, including buildings, bridges, hospitals, airports, highways, lifelines, and others. Accurate estimates of structural instrumentation needs are best derived using detailed inventories. Pending development of such estimates one proxy for the amount of structural instrumentation is the population exposed annually to $0.1 \mathrm{~g}$. These numbers as specified for ground shaking and corrected for soil amplification suggest that more than 6000 structures need to be instrumented.

Recent consensus of a national workshop concerned with the nation's capability to obtain the needed recordings of damaging shaking concluded that instrumentation for some 20,000 sites is needed (Stepp, 1997). Workshop consensus suggested that instrumentation is needed to record: ground shaking at about 7000 sites, building performance at another 7000 sites, lifeline performance including bridges, pipelines, and electric transmission facilities at about 3000 sites, critical facilities, specific emergency response, and damage assessment locations at an additional 3000 sites.

This number though large needs to be considered in the context of population exposed annually, potential losses from future earthquakes, and present retrofit expenditures expected to exceed several billion dollars over the next decade. The scope of effort implied by this amount of instrumentation far exceeds the present level of resources being expended in the United States to provide on-scale measurements of the next tragic earthquake. This discrepancy and the urgency of this national need argue strongly that present 
efforts need to be augmented wherever possible and major efforts need to be mounted to ensure that the next major event is recorded appropriately.

Table 1. Ground-motion instrumentation estimated for the United States.

\begin{tabular}{|c|c|c|c|c|c|c|}
\hline State & & $\begin{array}{l}\text { Population } \\
\text { Ann. Exp. } \\
\text { to } 0.1 \mathrm{~g} \\
\end{array}$ & $\begin{array}{l}\text { Instru. } \\
\text { Ann. Exp. } \\
\text { Pôp. } \\
\end{array}$ & $\begin{array}{l}\text { Instru. } \\
\text { Ann. Exc. } \\
\text { Râté } \\
\end{array}$ & $\begin{array}{l}\text { Max Instr wrt } \\
\text { Pop.Exp. \& } \\
\text { Aunin Exc Râte } \\
\end{array}$ & $\begin{array}{l}\text { Max Instr } \\
\text { Incl. Amplif. } \\
\text { Effects }\end{array}$ \\
\hline Alabama & $\mathrm{AL}$ & 1083 & 3.7 & 5.0 & 6 & 9 \\
\hline Arizona & $\mathrm{AZ}$ & 1428 & 4.8 & 13.4 & 13 & 20 \\
\hline Arkansas & $\mathrm{AR}$ & 2246 & 7.6 & 25.0 & 26 & 39 \\
\hline California & $\mathrm{CA}$ & 883292 & 2984.1 & 2538.4 & 4404 & $5505 *$ \\
\hline Colorado & $\mathrm{CO}$ & 555 & 1.9 & 1.1 & 2 & 3 \\
\hline Connecticut & $\mathrm{CT}$ & 2117 & 7.2 & 3.3 & 7 & 11 \\
\hline Delaware & $\mathrm{DE}$ & 199 & 0.7 & 0.3 & 1 & 1 \\
\hline D. of Columbia & $\mathrm{DC}$ & 48 & 0.2 & 0.0 & 0 & 0 \\
\hline Florida & FL & 791 & 2.7 & 0.8 & 3 & 4 \\
\hline Georgia & GA & 2805 & 9.5 & 9.6 & 13 & 20 \\
\hline Idaho & ID & 1034 & 3.5 & 26.6 & 27 & 40 \\
\hline Illinois & IL & 5887 & 19.9 & 40.5 & 49 & 73 \\
\hline Indiana & IN & 1384 & 4.7 & 7.1 & 9 & 13 \\
\hline Kansas & $\mathrm{KS}$ & 153 & 0.5 & 0.4 & 1 & 1 \\
\hline Kentucky & $\mathrm{KY}$ & 1955 & 6.6 & 22.8 & 24 & 35 \\
\hline Louisiana & LA & 271 & 0.9 & 0.3 & 1 & 1 \\
\hline Maine & ME & 590 & 2.0 & 3.7 & 4 & 5 \\
\hline Maryland & $\mathrm{MD}$ & 1389 & 4.7 & 1.6 & 5 & 7 \\
\hline Massachusetts & MA & 3734 & 12.6 & 4.4 & 13 & 19 \\
\hline Michigan & MI & 561 & 1.9 & 0.4 & 2 & 3 \\
\hline Minnesota & $\mathrm{MN}$ & 16 & 0.1 & 0.0 & 0 & 0 \\
\hline Mississippi & MS & 215 & 0.7 & 2.0 & 2 & 3 \\
\hline Missouri & MO & 4377 & 14.8 & 28.7 & 36 & 54 \\
\hline Montana & MT & 958 & 3.2 & 63.2 & 63 & 95 \\
\hline Nebraska & $\mathrm{NE}$ & 144 & 0.5 & 0.3 & 1 & 1 \\
\hline Nevada & NV & 4598 & 15.5 & 112.8 & 113 & 113 \\
\hline New Hampshire & NH & 1284 & 4.3 & 4.9 & 6 & 9 \\
\hline New Jersey & NJ & 10449 & 35.3 & 6.2 & 36 & 53 \\
\hline New Mexico & NM & 1433 & 4.8 & 8.1 & 9 & 14 \\
\hline New York & NY & 12207 & 41.2 & 13.8 & 46 & 69 \\
\hline North Carolina & NC & 3180 & 10.7 & 16.4 & 18 & 27 \\
\hline Ohio & $\mathrm{OH}$ & 2453 & 8.3 & 4.3 & 9 & 13 \\
\hline Oklahoma & OK & 794 & 2.7 & 2.1 & 3 & 5 \\
\hline Oregon & OR & 10526 & 35.6 & 124.4 & 130 & 196 \\
\hline Pennsylvania & PA & 4909 & 16.6 & 6.5 & 17 & 25 \\
\hline Rhode Island & RI & 464 & 1.6 & 0.6 & 2 & 2 \\
\hline South Carolina & $\mathrm{SC}$ & 5558 & 18.8 & 42.8 & 43 & 65 \\
\hline Tennessee & $\mathrm{TN}$ & 7185 & 24.3 & 47.7 & 54 & 81 \\
\hline Texas & TX & 1355 & 4.6 & 1.7 & 5 & 7 \\
\hline
\end{tabular}


Table I continued

\begin{tabular}{|c|c|c|c|c|c|c|}
\hline Utah & UT & 8409 & 28.4 & 38.5 & 48 & 72 \\
\hline Vermont & VT & 224 & 0.8 & 1.8 & 2 & 3 \\
\hline Washington & WA & 39802 & 134.5 & 252.0 & 281 & 422 \\
\hline West Virginia & WV & 424 & 1.4 & 1.6 & 2 & 3 \\
\hline Wisconsin & WI & 540 & 1.8 & 1.0 & 2 & 3 \\
\hline Subtotal & & 1033026 & 3490.0 & 3486.0 & 5536 & 7,146 \\
\hline Alaska & & & 75.0 & 75.0 & 125 & 188 \\
\hline Hawaii & & & 50.0 & 50.0 & 75 & 113 \\
\hline Puerto Rico & & & 50.0 & 50.0 & 75 & 113 \\
\hline Total & & $\overline{1033026}$ & $\overline{3665}$ & $\overline{3661}$ & $\overline{5811}$ & 7558 \\
\hline
\end{tabular}

\section{Strong-Motion Instrumentation Needs -- As Estimated in Detail on a Regional Scale}

Strong-motion instrumentation needs can be readily illustrated and best understood upon consideration of the recording needs for specific earthquakes on a regional scale. Modern methodologies permit estimates of both shaking and resultant losses for specific earthquakes. These estimates provide a rigorous basis to determine where instruments should be located in order to record adequately record the event for both hazard mitigation and emergency response purposes.

A repeat of the 1906 earthquake in the San Francisco Bay region is chosen here to illustrate the detailed assessment of instrumentation needs for a particular region and a particular event. Similar assessments are needed for each region with significant population exposure to strong seismic shaking from various sources.

The San Francisco Bay area is an area with an especially high annual population exposure to strong ground shaking (see Figure 1). It is an area for which the distribution and type of modern structures recently damaged by a moderate earthquake are well known. It is an area for which extensive estimates of ground shaking based on up-to-data geologic maps and resultant losses for a repeat of the 1906 earthquake have been recently estimated (RMS, Inc., 1994; Borcherdt, et al., 1995). Its proximity to major faults with high earthquake potential and dense concentration of population provides substantial insight as to the instrumentation needed in order to record the next earthquake so as to meet the needs of society.

Ground motion estimates for a repeat of the California earthquake of April 18, 1906 accounting for variations in local geology are predicted in terms of spectral response at 1.0 and 0.3 seconds (Figures 2a, 2b, 2c, and 2d; from Borcherdt, et al., 1995). Superimposed on the maps are locations of the built environment, which includes major buildings (Figure 2a), transportation facilities (highways, bridges, airports, and streets; Figure 2b), schools and hospitals (Figure 2c), and hazardous material sites (Figure $2 \mathrm{~d}$ ). Consideration of the geographic distribution of the built environment with that for strong shaking helps define areas of most interest for instrumentation. Application of GIS technology permits efficient and thorough evaluation of the potential exposure of various components of the built environment to damaging levels of shaking. A detailed evaluation is provided first for the City and county of San Francisco to permit illustration at a scale of a few city blocks needed to show the location of major structures. 


\section{Instrumentation to Record Anticipated Ground Shaking Variations and Resultant Losses in the City of San Francisco}

The ground-shaking maps (Figures $2 \mathrm{a}-2 \mathrm{~d}$ ) show that strong ground shaking varies rapidly with increasing distance from the source and type of geologic conditions. It shows that ground-shaking at periods of 1 second may decrease by more that an order of magnitude within a distance of $15 \mathrm{~km}$ from the source for sites on rock. The map illustrates that for instrumentation to record damaging levels of ground shaking on rock, it must be located within $20 \mathrm{~km}$ of the source. It shows that to document rapid variations in shaking due to local geology that may range from violent to weak, instrumentation must be placed in some locations at spacing of 1 or 2 city blocks.

A detailed instrumentation plan to document the major variations in ground shaking throughout the City of San Francisco is shown in Figure 3a. This plan illustrates the location and number of instruments required to provide thorough documentation of expected spatial variations in shaking (Borcherdt and others, 1997). The map illustrates that about 181 stations are needed. For comparison the estimate derived on a national scale implies 42 instruments for the city and county of San Francisco. The spacing of the instrumentation implied by the national estimate is illustrated by the superimposed grid with a spacing of $1.7 \mathrm{~km}$, which corresponds to about 35 stations per $100 \mathrm{~km}^{2}$. The number of 181 shown here emphasizes the number derived on a national scale is a minimal number.

A detailed instrumentation plan based on the geographic distribution of residential and commercial losses estimated for a repeat of the 1906 earthquake is shown for the city of San Francisco in Figure 3b (Risk Management Solutions, Inc., pers. commun., 1997). The estimates are based on detailed inventories of the built environment and associated assessed vuinerabilities. The estimated losses are shown in units of $\$ 1,000$ per approximately $1 / 2$ city block. The map shows that the highest expected losses are concentrated in downtown San Francisco. The concentration of severe losses in parts of downtown San Francisco suggests that instrumentation in these areas should be relatively dense and not more than a few blocks apart. The resultant instrumentation considered necessary to thoroughly document ground shaking throughout the areas of large loss is about 110 locations. Comparison of this amount with that (42) implied by the national estimate shows that the national estimate is a minimal estimate for areas of high population exposure and soft soils.

The instrumentation plans illustrated here for the City of San Francisco emphasize the need to install instrumentation at a large number of sites throughout the city in order to quantitatively measure rapid and large spatial variations expected in ground shaking throughout the area. These considerations suggest that needed resource levels are much greater than presently available.

Instrumentation to Measure the Shaking Performance of the Built Environment in the southern San Francisco Bay region

Hazard mitigation though the design, construction, and retrofit of earthquake resistant structures and nearreal time disaster assessment both require that the performance of man-made structures be measured thoroughly throughout the strongly shaken area. Consideration of the geographic distribution of the built environment relative to expected shaking levels helps provide insight as to where instrumentation is needed.

The geographic distribution of various components of the built environment relative to various anticipated levels of shaking are illustrated in Figures $2 \mathrm{a}-2 \mathrm{~d}$. The number and percentages of buildings, transportation facilities, schools and hospitals and hazardous material sites exposed to various levels of shaking are summarized in Tables $2 \mathrm{a}$ and $2 \mathrm{~b}$. They show that a significant percentage of each type of major facility is located in zones expected to experience damaging levels of motion. 
Table 2a Number of major facilities in the southern San Francisco Bay region expected to experience various levels of spectral acceleration at 1.0 second for a repeat of the 1906 earthquake ( $\mathbf{M w}=7.7)$.

\begin{tabular}{|c|c|c|c|c|c|c|c|}
\hline \multirow{2}{*}{$\begin{array}{c}\mathrm{Sa} @ 1.0 \mathrm{~s} \\
(\mathrm{~g})\end{array}$} & \multirow{2}{*}{$\begin{array}{c}\text { MM scale } \\
\text { (approx.) }\end{array}$} & \multicolumn{2}{|c|}{ Bridges } & \multicolumn{2}{|c|}{ Airports } & \multicolumn{2}{|c|}{ Hazardous Materials } \\
\hline & & Number & Percent & Number & Percent & Number & Percent \\
\hline$>1.0$ & $\mathrm{X}$ & 272 & 25 & 4 & 25 & 17 & 7 \\
\hline $0.6-1.0$ & $\mathrm{VII}+-\mathrm{IX}$ & 221 & 20 & 7 & 44 & 35 & 15 \\
\hline $0.3-0.6$ & $\mathrm{VII}-\mathrm{VII}+$ & 484 & 45 & 4 & 25 & 178 & 76 \\
\hline$<0.3$ & $<\mathrm{VI}+$ & 102 & 9 & 1 & 6 & 3 & 1 \\
\hline Total & & 1079 & 100 & 16 & 100 & 233 & 100 \\
\hline
\end{tabular}

Table 2b Number of hospitals, and schools in the southern San Francisco Bay region expected to experience various levels of spectral acceleration at 1.0 second for a repeat of the 1906 earthquake $(\mathrm{Mw}=7.7)$.

\begin{tabular}{|c|c|c|c|c|c|}
\hline \multirow{2}{*}{$\begin{array}{c}\mathrm{Sa} @ 1.0 \mathrm{~s} \\
(\mathrm{~g})\end{array}$} & \multirow{2}{*}{$\begin{array}{c}\text { MM scale } \\
\text { (approx.) }\end{array}$} & \multicolumn{2}{|c|}{ Hospitals } & \multicolumn{2}{|c|}{ Schools } \\
\hline & & Number & Percent & Number & Percent \\
\hline$>1.0$ & $\mathrm{X}$ & 14 & 14 & 121 & 15 \\
\hline $0.6-1.0$ & $\mathrm{VII}+-\mathrm{IX}$ & 34 & 34 & 261 & 33 \\
\hline $0.3-0.6$ & VII - VII + & 41 & 41 & 345 & 43 \\
\hline$<0.3$ & $<\mathrm{VI}+$ & 10 & 10 & 74 & 9 \\
\hline Total & & 99 & 100 & 801 & 100 \\
\hline
\end{tabular}

Percentages of the highways, bridges and railways located on the various soil and rock site classes defined for the 1994 Recommend Building Code provisions are summarized in Table 3. They show that $69 \%$ of the bridges, $57 \%$ of the highways, and $100 \%$ of the railways are located on either stiff clays and sandy soils or on soft clays known locally as "Bay Mud".

Table 3. Percentage of bridges, highways, and railways in southern San Francisco region located in each site classes defined in 1994 NEHRP Recommended Building Code Provisions.

\begin{tabular}{|c|c|c|c|c|}
\hline \multicolumn{2}{|c|}{ Site Class } & \multirow{2}{*}{$\begin{array}{l}\text { Bridges } \\
\text { percent }\end{array}$} & \multirow{2}{*}{$\begin{array}{c}\text { Highways } \\
\text { percent }\end{array}$} & \multirow{2}{*}{$\begin{array}{c}\text { Railways } \\
\text { percent }\end{array}$} \\
\hline NEHRP & Description & & & \\
\hline B & Firm-Hard rock & 9.3 & 10.7 & 0 \\
\hline $\mathrm{C}$ & Soft rock \& Gravely soils & 21.3 & 32.1 & 0 \\
\hline D & Stiff clays \& Sandy soils & 50.9 & 42.9 & 81.3 \\
\hline $\mathrm{E}$ & Soft soils & 18.5 & 14.3 & 18.7 \\
\hline
\end{tabular}

The high amplification capability and high liquefaction susceptibility of some of these soil deposits contributes significantly to the vulnerability of the residing structures. These results show that 
instrumentation to measure the response of transportation facilities must be located mostly on soil deposits and would not be useful for seismicity studies.

Superposition of the built environment on the statistics compiled for the southern San Francisco Bay region show that a large percentage of the built environment is located in areas for which the shaking levels are expected to exceed $0.6 \mathrm{~g}$ in spectral response acceleration at 1.0 second. Statistics for hospitals and schools in the city of San Francisco are summarized in Table 4.

Table 4 Percentage of schools and hospitals in the county of San Francisco exposed to various levels of short-period $(0.3 \mathrm{sec})$ spectral-response acceleration.

\begin{tabular}{|c|c|c|c|c|c|}
\hline \multirow{2}{*}{$\begin{array}{c}\mathrm{Sa} @ 1.0 \mathrm{~s} \\
(\mathrm{~g})\end{array}$} & \multirow{2}{*}{$\begin{array}{c}\text { MM scale } \\
\text { (approx.) }\end{array}$} & \multicolumn{2}{|c|}{ Hospitals } & \multicolumn{2}{|c|}{ Schools } \\
\hline & & Number & Percent & Number & Percent \\
\hline$>1.0$ & $\mathrm{X}$ & 6 & 30 & 121 & 15 \\
\hline $0.6-1.0$ & $\mathrm{VII}+-\mathrm{IX}$ & 8 & 40 & 261 & 33 \\
\hline $0.3-0.6$ & VII - VII + & 3 & 15 & 345 & 43 \\
\hline$<0.3$ & $<$ VI+ & 3 & 15 & 74 & 9 \\
\hline Total & & 20 & 100 & 801 & 100 \\
\hline
\end{tabular}

Such areas located mostly on soils in the flatiand areas of the region can be expected to be associated with intensity levels from the past experience of the 1906 earthquake ranging from strong to violent. A summary of statistics in Table 5 shows that of $45 \%$ of the 1079 bridges, $69 \%$ of the 16 airports, $22 \%$ of the 233 hazardous material sites, $48 \%$ of the 99 medical facilities, and $48 \%$ of the 801 schools are located in areas expected to experience these damaging levels of shaking. This number of 986 sites suggests a significant component of the built environment in the San Francisco Bay region will experience damaging levels of ground shaking during a repeat of the 1906 earthquake. In addition, a significant number of buildings corresponding to the locations shown in Figure $2 \mathrm{a}$ also will experience damaging levels of shaking. Present database does not permit differentiation of the height and type of building, but does provide the number and location of major buildings (Figure 2a). The database indicates that a arge number of buildings $(>3000)$ will experience damaging levels of shaking.

The large percentages of important structures including buildings located in areas of potentially damaging ground shaking suggest that a large number of sites need to be instrumented in order to thoroughly measure the seismic performance of the built environment. An instrumentation plan to thoroughly document the performance of the built environment in the heavily damaged area must consider each of the more than 4000 sites expected to experience damaging levels of shaking as serious contenders for instrumentation. If only 10 percent of these structures were instrumented, then about 400 structures need to be instrumented in the southern San Francisco Bay region in order to measure the seismic performance of the built environment to a repeat of the 1906 earthquake. The tabulation for hospitals and schools in the city of San Francisco (Table 4) emphasizes this conclusion. It shows that $70 \%$ of the hospitals and $48 \%$ of the schools are expected to experience $0.6 \mathrm{~g}$ or greater spectral accelerations.

These considerations of the instrumentation needed to measure the performance of the built environment suggest that needed resource levels are much greater than presently available.

Instrumentation for Disaster Assessment and Near Real Time Emergency Response for the southern San Francisco Bay region

Reduction of loss of life and property immediately following earthquake disasters can be dramatically improved if the location and severity of damages can be rapidly assessed. Modern instrumentation technology now permits such assessments to be made in densely urbanized areas within a few minutes of 
the occurrence of the event. Such quick assessments can significantly improve emergency response capabilities. Rapid assessments can speed-up treatment of injuries, reduce the number of casualties, facilitate evacuations, if flooding or fire are imminent, and permit more rapid and efficient deployment of emergency operations.

Modern instrumentation with telecommunication capabilities permits areas of strongest shaking and the performance of structures to be quickly assessed. Instruments on structures such as buildings, bridges, freeway overpasses, and dams permit rapid assessment of probable Damage State within a few tens of seconds of the start of shaking. Such rapid information permits efficient dispatch and routing of emergency response resources. Measurements on lifelines such as electric power transmission facilities, gas and oil lines, and rapid transit facilities allow efficient shut down and prevention of additional disaster. Reducing the time for disaster assessment and resultant emergency response from hours to a few minutes can save untold amounts of life and property. Important examples illustrating the application of modern technology to disaster reduction now exist for Yokohama, Japan and a few other public and private agencies.

Instrumentation deployed for near-real time disaster assessment purposes must necessarily be located on and near structures in the heavily damaged urbanized areas. Instrumentation in such locations also can serve to provide the strong-motion recordings of the main earthquake needed for improved earthquake resistant construction and hazard mitigation. Equipping selected strong-motion stations with appropriate telecommunication capabilities could be a cost-effective means of improving emergency response and thereby reducing the disastrous effects of future earthquakes.

Ground-Motion Instrumentation -- Instrumentation deployed to assess ground shaking levels and their potential impact on the built environment for purposes of disaster assessment must be deployed throughout the urbanized areas likely to experience damaging levels of shaking. Instrumentation on a grid with spacing of $2 \mathrm{~km}$ is being used for the network installed in Yokohama, Japan. This spacing allows rapid decisions on a scale appropriate for rerouting of emergency vehicles. It permits relatively thorough measurement of spatial variations in shaking. It is slightly larger than the $1.7 \mathrm{~km}$ spacing specified for the cells of highest population exposure used herein to derive the national estimate. It suggests that some $50-85 \%$ of the strong-motion instrumentation installed for ground-motion measurement purposes in cells of highest population exposure should be equipped with near-real time communication capabilities.

Structural Instrumentation Estimate--Structural instrumentation deployed to measure seiismic performance, if equipped with rapid communication capabilities, can also serve disaster assessment and critical emergency response purposes. An effective disaster assessment capability requires that instrumentation be installed on and throughout various critical structures, in order that the damage state of the structures can be assessed and appropriate emergency actions taken. Rapid knowledge of the extent to which critical structures such as bridges, highway overpasses, hospitals, emergency response centers, telecommunication centers, fire stations, power facilities and others are damaged is especially important for emergency response purposes. An essential aspect of any near-real time earthquake hazard monitoring effort must necessarily be an instrumentation network established with locations on and at critical facilities. Many of the sites chosen for measurement of strong ground shaking can be chosen near critical facilities in order to serve a dual monitoring purpose.

Consideration of the geographic distribution of the built environment for the southern San Francisco Bay provides some insight as to the amount and distribution of instrumentation needed for disaster assessment and emergency response purposes. The maps (Figures $2 \mathrm{a}, 2 \mathrm{~b}, 2 \mathrm{c}$, and $2 \mathrm{~d}$ ) suggest some 25 to 50 percent of the instrumentation installed to monitor the seismic performance of the structure should also be used to assess the damage state of the structures in near-real time. Instrumentation equipped with near-real time telecommunication capabilities at these sites would serve the dual purposes of hazard mitigation and improved emergency response. 


\section{II -- REGIONAL AND NATIONAL NETWORK EARTHQUAKE RECORDING EFFORTS}

The scope of effort implied by instrumentation needed at some 20,000 sites far exceeds the present level of resources being expended in the United States to record the next tragic earthquake at the locations of most significance for society. This discrepancy and the urgency of this national need argue strongly that present efforts need to be augmented wherever possible. Resources as currently available in national and regional seismic networks and in the state and federal strong-motion programs are reviewed. A detailed description of the NSMP as operated by the USGS is described in the next section.

\section{NATIONAL AND REGIONAL SEISMIC NETWORKS}

An extensive set of networks have evolved over the last 21/2 decades with the principle objectives pertaining to the recording of weak ground motions generated by earthquakes. The principal objectives of these networks include seismicity location, crustal structure, tectonic studies, core and mantle structure, nuclear weapon explosion detection, dam loading, fluid injection, and others. Each of these objectives requires that the stations be located at seismically quiet sites away from man-made cultural noise sources. The stations are, for the most part, underlain by rock in parks and remote hilly areas away from cultural disturbances associated with buildings, highways, bridges, and other structures with high population exposure.

Individual universities and the USGS operate the regional networks. In addition, a national seismic network comprised of broadband stations useful for monitoring seismicity on a global basis is operated by the USGS in cooperation with the IRIS A consortium of the national network and the regional networks has been organized as the Council for the National Seismic System. This consortium comprises 2115 stations as recently compiled by Malone (pers. commun., 1997). Of the total number of stations, 1772 stations are classified as short-period regional stations, 183 are classified as broadband stations, and 160 as digital strong-motion stations.

To investigate the possible use of these sites as sites to provide strong-motion recordings, the locations of the short-period and broadband stations are plotted on the map showing the annual exceedance rate for $0.1 \mathrm{~g}$ ground motion level (Figure 4a; from Frankel et al., 1996; Borcherdt, et al., 1997). The maps are colored so that areas for which the annual rate of exceedance is less than 0.01 is shown in blue. On the average areas shown in blue or with no color would not be expected to experience ground shaking levels as high as $0.1 \mathrm{~g}$ within 100 years. For areas shown in yellow and orange, ground motions would be expected on the average to reach the $0.1 \mathrm{~g}$ level at least once during a 100 -year interval. The map indicates that some stations in California, a few in Washington, Nevada, and Montana are located in cells of $100 \mathrm{~km}^{2}$ that are likely to experience ground motions greater than $0.1 \mathrm{~g}$ in 100 years

To further evaluate the possibility of using network stations as strong-motion sites the shori-period, broad-band and stations termed digital strong-motion are superimposed on maps for the coterminous US (Figure 4b) and California (Figure 4) showing average annual population exposure to $0.1 \mathrm{lg}$ (Figure $4 \mathrm{~b}$; Borcherdt, et al., 1997). The population exposure per 100 square kilometers is used as a proxy for the exposure of the built environment. Evaluation of the station distribution shown on the two maps shows that a majority of the network stations including the stations termed digital strong motion do not tend to be distributed according to population exposure, but instead show a more uniform distribution. Evaluation of the network station distribution at this scale suggests that a majority of the stations would not be expected to experience $0.1 \mathrm{~g}$ during a 100 year time interval. A small percentage, perhaps 10 percent are located in 100 square $\mathrm{km}$ cells for which the annual population exposure to a $0.1 \mathrm{~g}$ exceedance level is expected to reach relatively high levels of about 2000 people.

To investigate possible locations for strong motion instrumentation one step further the locations of the network stations are superimposed on the predicted ground shaking map for a repeat of the 1906 earthquake (Figure 2d). This map shows one station at the Presido in the city of San Francisco and 12 stations located on rock in the hills above the urbanized area of the San Francisco peninsula that could be 
expected to experience spectral accelerations corresponding to pga levels greater than $0.1 \mathrm{lg}$. The map shows these 12 sites, if equipped with industry accepted strong-motion instrumentation, could be used to record damaging levels of motion. Recordings at these sites would be of interest for studying the nature of near-source seismic radiation, but not for ground motion measurement for purposes of damage assessment or performance of the built environment.

Consideration of the location of stations at a detailed scale shows that the locations required for the regional and national network stations are, with the exception of a few stations, not appropriate for strongground motion measurement purposes. Stations located for purposes of monitoring seismicity are necessarily located away from cultural noise sources at sites underlain by firm to hard rock. Strongmotion stations must be located near or on man-made structures in areas with high cultural background noise levels, which are often underlain by soils. This evaluation clearly establishes that network stations installed to monitor seismicity have necessarily been located at sites not of a high priority to society for purposes of measuring of strong-motion.

This important conclusion has several implications with respect to the design and maintenance of future networks. The difference in the seismic background noise level at the two types of sites implies that different sites must be used to meet the different monitoring objectives of the EHRP. For the most part the sites used to meet strong-motion measurement needs are different than those used to meet seismicitymonitoring needs.

The fact that different sites must be used to meet the different monitoring needs implies that different types of instrumentation also are best suited to serve the different purposes of the EHRP. Instrumentation designed to meet all needs is not cost effective nor best suited to meet the specific purposes chosen for the different types of sites, even though modern instrumentation is ever improving and becoming more versatile. Seismicity-monitoring equipment needs to be highly sensitive with continuous telemetry. Only those seismicity stations located on rock at distances less than $20 \mathrm{kms}$ from large potential earthquake sources need be concerned with installing strong-motion accelerometers and on-site recording capabilities. Similarly, strong-motion stations installed near or on man-made structures underlain by soil in densely urbanized areas need not be installed with highly sensitive sensors to record distant seismicity. Each strong-motion station must be equipped with on-site recording capability, but need not be equipped with capabilities to send all waveforms via telecommunication because of telemetry costs. Stations installed for disaster assessment purposes and near-real-time emergency response must be installed on and near man-made structures, such as bridges, hospitals, etc. These stations must be equipped to both record strong shaking on-scale and rapidly communicate this information via telecommunication lines to emergency response centers. These strong-motion stations should be equipped with telemetry capabilities that permit a variety of travel-time, amplitude, and duration parameters to be transmitted in near-real time. These distinctions in the types of instrumentation imply that the different types of stations must be designed and maintained with specific objectives in mind in order to be as cost-effective as possible.

Another difficulty in the use of various on-scale measurements for earthquake resistant design and retrofit practice is that only certain types of on-scale measurements are usable presentily by the industry. Liability associated with the design and interpretation of the codes has led to the use of only data recorded on particular types of instruments and processed according to a uniform set of standards established by the Earthquake Engineering Community. Incorporation of any on-scale measurements that might be made in the future on network stations would require that a similar set of instrumentation and data processing standards for network data be established so as to represent a consensus in order to be useful to the industry.

\section{COORDINATION OF SEISMIC NETWORKS}

For the past 25 years seismologists have operated two different types of networks to fulfill two different missions. On-scale recordings of strong ground motion, which are of great interest to the engineering 
community, are typically obtained from non-telemetered event recorders. These instruments are designed to record the main event. This requirement implies that the instrumentation must permit on site recording capability, because of shaking vulnerabilities of telemetry equipment. The need to locate these instruments in noisy locations implies that the collection of information on the more frequently occurring, but smailer quakes is not possible. In contrast, weak-motion seismic networks fulfill the need for rapid reporting on felt but not necessarily the main earthquake, volcanic seismicity, and research topics such as earthquake prediction, earth structure, stress, and geothermal phenomena. The need for real-time recording of earthquakes of all magnitudes requires telemetry to transmit either a set of inferred parameters or a continuous stream of seismometer output to a central recording site. However, the analog telemetry traditionally used by weak-motion networks invariably produces a clipped record for any earthquake exceeding magnitude (M) 2 at distances less than $25 \mathrm{~km}$ and $\mathrm{M}>3.5$ at distances less than $100 \mathrm{~km}$. Clearly, this information is of limited use for applications requiring on-scale measurements.

Because of different objectives, different types of recording sites and different user communities, separate groups have operated weak-motion and strong-motion networks. However, new mandates to the seismological community emphasize urban hazard mitigation and rapid damage assessment following large earthquakes. Presently, far more NEHRP resources are devoted to weak-motion networks than to strongmotion networks. This imbalance probably arose because small earthquakes are quite common, and resources and research interests naturally gravitated towards instrument installations that could provide recordings in the short term. Also, the impact of earthquakes on urban environments was appreciated more fully once the impact of recent earthquakes such as the 1989 Loma Prieta earthquake was observed on modern urban environments.

The Loma Prieta quake demonstrated the need for more strong-motion recordings in and near manmade structures in damaged urbanized areas. The Northridge and Kobe earthquakes emphasized this need to an even greater extent. The Kobe earthquake prompted dramatic increases in expenditures in Japan to record strong motion. More than 2000 strong-motion stations have been installed in Japan since the earthquake at costs exceeding 20 million US dollars. The principal objective of each of these stations is the on-scale measurement of the main earthquake, but not necessarily the measurement of weak-motion small or distant events. This expenditure and focus emphasizes the critical and urgent need for strong-motion recordings identified earlier in this report.

Weak-motion networks in the US are now upgrading their instrumentation to take advantage of improvements in digital technology and communication. These networks are now installing data loggers capable of recording the full dynamic range of seismic signals, strong motion sensors to ensure the recording of on-scale data during the largest events, and employing digital telemetry. Hence, former "weak-motion" networks are more properly becoming "regional" networks with the capability of recording on-scale motions. Similarly, the strong-motion networks are taking advantage of auto-dialing sontware to rapidly retrieve digital data from event recorders. Still, the missions of the regional and strong-motion networks are quite different, and consequently their station locations are often of limited use to each other as discussed here and shown in previous sections. Consequently, it is important to use modern technology to rapidly exchange and communicate information between the two types of networks, but at the same time maintain their integrity of purpose in order that their objectives can be achieved and the earthquake recordings needed by society can be obtained.

Efforts are underway in California to coordinate instrument upgrade efforts and siting of new instruments. In southern California the TriNet program is a cooperative agreement between the California Strong Motion Program (CSMIP), the Southern California Seismic Network (SCSN) operated by the USGS and the California Institute of Technology, and the USGS National Strong Motion Program (NSMP). Data will be shared between all three groups, and instrumentation efforts are coordinated through a working group. The main objectives of the TriNet project include 1) the expansion and upgrade of the measurement of ground motions, 2) directed analysis studies of strong shaking to improve seismic provisions in building 
codes, 3) development of real-time analysis capability to provide earthquake parameters and strong shaking maps for significant earthquakes, and 4) development of a prototype early warning system.

A similar cooperative effort is being formed in northern California between CSMIP, the Northern California Seismic Network operated by the USGS, NSMP, and the University of California Berkeley which operates the Berkeley Digital Seismic Network (BDSN). In both regions of California, all the network operators recognize that each network contributes unique information about the earthquake process. For example, the on-line computer systems of the NCSN and BDSN are linked via a dedicated frame-relay line, and each network jointly participates in monitoring of earthquakes, notification, and information distribution. In addition to short-period seismometers and broadband sensors, both networks operate accelerometers at the surface and at down-hole sites. They are also working to integrate information via dial-up telemetry to retrieve on-scale data from event recorders operated by the Pacific Gas and Electric Corporation and the NSMP in northern California. The result of these coordinated efforts will enable on-scale measurements from all instruments to be available shortly after the occurrence of a significant event. This information can be quickly put to use for a variety of uses ranging from the automated generation of shaking maps to spectral response at critical facilities.

\section{EXISTING STRONG-MOTION PROGRAMS}

A thorough review of strong-motion programs in the United States (Stepp, 1997) shows that the total number of stations currently operated for a variety of different objectives is less than 2000 stations. This number includes stations installed in buildings and dams for code and monitoring purposes. This number is an order of magnitude smaller than that reviewed herein and recommended by the national workshop (Stepp, 1997). This discrepancy and the urgency of this national need argue strongly that present efforts need to be augmented wherever possible. It indicates that urgent and major efforts are needed to increase the amount of resources devoted to strong-motion data acquisition, processing, and dissemination. It indicates that significant efforts are needed to best utilize existing EHRP resources to meet this important national need. Detailed maps of existing strong-motion stations are provided in the next section.

\section{III -- THE NATIONAL STRONG-MOTION PROGRAM -- A NATIONAL PROGRAM TO ACQUIRE AND MAINTAIN AN ON-SCALE MEASUREMENT STANDARD AND DATABASE FOR PUBLIC EARTHQUAKE SAFETY}

The National Strong-Motion Program of the United States is operated by the US Geological Survey as part of the National Earthquake Hazard Reduction Program authorized by the Earthquake Hazard Reduction Act of 1978. The program operates a cooperative National Strong-Motion Network (NSMN), the National Strong-Motion Data Center (NSMDC), and a basic data interpretation and research capability. The program has primary Federal responsibility for the acquisition and dissemination of all on-scale measurements of damaging levels of shaking for large earthquakes in the United States. The program maintains a data standard and database as the basis for all of the earthquake resistant design and retrofit industry. The program has primary responsibility for on-scale measurements of damaging shaking pertaining to physics of seismogenic rupture, wave propagation, site response, soil-structure interaction, and structural response.

\section{BRIEF HISTORY}

The NSMP initiated with discussions at the World Engineering Congress in 1929. Congress appropriated initial funding for the program to the U.S. Coast and Geodetic Survey in 1931. The first accelerographs were installed in Southern California in 1932 in time to provide the first strong-motion recordings of the Long Beach earthquake of 1933. The U.S. Coast and Geodetic Survey operated the program until 1973, at which time personnel and funding responsibilities were officially transferred to the U. S. Geological 
Survey and the National Science Foundation, respectively. Funding responsibility for the program was transferred from the National Science Foundation to the U. S. Geological Survey in 1983.

\section{CONTRIBUTIONS OF THE STRONG-MOTION PROGRAM TO THE ASSESSMENT OF EARTHQUAKE HAZARDS AND THE REDUCTION OF EARTHQUAKE LOSSES.}

An essential basis for all of earthquake engineering is the strong-motion records collected by the National Strong Motion Program and other strong-motion recording programs, particularly the California Strong Motion Insrtumentation Program (CSMIP). For 30 years the El Centro record of the 1940 Imperial Valley earthquake was the basis for earthquake resistant design. Strong-motion records from the San Fernando earthquake of 1971 and the Imperial Valley earthquake of 1979 made possible the first reliable ground-motion prediction equations. These equations, in turn, make possible the seismic hazard maps used in building codes and in earthquake loss estimation.

Strong-motion recordings obtained either directly by the NSMP, through the cooperative efforts of the NSMP or within the last decade by the CSMIP provide the basis for understanding the physics of seismogenic failure in the earths crust and the causative radiation as ground shaking. They are the basis for predicting damaging levels of shaking in future earthquakes and the basis for understanding the response of the built environment to damaging shaking.

Strong-motion recordings in structures have lead to many advances in earthquake-resistant design. One example is the analysis of CSMIP recordings from a college gymnasium building (Celebi et al., 19??). The results indicated that the motion of the flexible roof diaphram was amplified, relative to the motion of the ground, by a much larger factor than provided for in the version of the building code current at that time. These studies led directly to code revisions.

Two major changes in the earthquake provisions of building codes in the past few years are directly attributable to strong-motion records. The site coefficients in the 1997 edition of the Uniform Building Code (UBC) and the 1994 and 1997 editions of the National Earthquake Hazard Reduction Program code provisions were based in significant part on strong-motion recordings from the 1979 Loma Prieta earthquake (see eg. Borcherdt, 1994 or Martin and Dobry, 1994). The near-source coefficient in the 1997 UBC, which brings about an increase of as much as a factor of two in the design base shear, was motivated entirely by the large near-source motions observed on strong-motion records.

For important structures, strong-motion records are used in analysis and design procedures that go beyond the codes. They are used for site specific design of major sturctures by most major earthquke enginnering firms. They permit site-specific dynamic analysis of structural performance and, in particular, nonlinear analyses. The need and use for strong motion records wiill continue to accelerate as more recordings are obtained. As a basis for all earthquake resistant design and construction, there is no substitute for an actual strong-motion recording of a similar event at or near a location of interest. As the number of recordings increase so will their contribution to earthquake loss reduction.

\section{PARTICIPATING AGENCIES AND INSTITUTIONS OF THE NSMP}

The NSMP coordinates and facilitates agency specific strong-motion data acquisition programs operated by a variety of federal, state, and local agencies, private companies, and academic institutions. The NSMP has formal network operational responsibility with 15 cooperative agencies (see Table 5) and 2530 private companies. Number of stations and accelerographs associated with the cooperative

\section{COOPERATIVE EFFORTS WITH THE CSMIP}

The California Division of Mines and Geology operates the California Strong-Motion Program (CSMIP) with basic funding provided by a state tax on permits for new construction. Recently, additional funding is being provided to the program for a 5-year time interval by the Federal Emergency 
Table 5. Participants of the National Strong-Motion Program operated by the U.S. Geological Survey.

\begin{tabular}{l|cc}
\hline Owner Agency & Stations & Accelerographs \\
\hline Army Corps of Engineers & 67 & 190 \\
Property Owner (Code mandated) & 31 & 35 \\
California Department of Water Resources & 04 & 07 \\
Department of Veterans Affairs & 59 & 77 \\
General Services Administration & 02 & 08 \\
Hawaii State Civil Defense & 05 & 05 \\
Metropolitan Water District of Southern California & 20 & 35 \\
Oregon Department of Transportation & 05 & 25 \\
University of Puerto Rico & 08 & 08 \\
U.S. Department of Energy & 01 & 06 \\
U.S. Geological Survey & 325 & 421 \\
Utah Geological Survey & 07 & 07 \\
Washington, City of Aberdeen & 01 & 03 \\
Washington, Tacoma Public Utilities & 01 & 03 \\
Washington Dept. of Natural Resources & 01 & 04 \\
Washington Department of Transportation & 03 & 06 \\
\hline TOTALS & 540 & 840 \\
\hline
\end{tabular}

participants are summarized. For more detailed information refer to http://agram.wr.usgs.gov/.

Management Agency (FEMA). This funding is for purchase and installation of approximately 400 strong-motion digital stations in southern California as part of the Tri-Net cooperative network

The CSMIP was initially set up and has been subsequently operated in close cooperation with the NSMP. The NSMP has major responsibility in the state of California for instrumentation of federal buildings and structures, some free-field and special ground-motion arrays, and some special soil-structure and structural research arrays. The CSMIP has major responsibility for instrumentation of typical buildings, state government buildings, state bridges, state highway structures, and ground-motion instrumentation in support of structural monitoring efforts. The CSMIP is legislated to emphasize instrumentation in and near typical structures, while the $N S M P$ has responsibilities regarding ground-motion arrays and arrays in structures for solution of special research issues important for earthquake hazard reduction on a national basis.

The need for instrumentation in both state and federal facilities and a several other non-overlapping objectives requires that both programs be operated in the State of California. The strong-motion measurement needs of society can not be met if either program were to discontinue operations in California.

\section{NATIONAL STRONG-MOTION NETWORK (NSMN)}

The National Strong-Motion Network (NSMN) of the NSMP is comprised of instrumentation located throughout the coterminous United States, Alaska, Hawaii, and Puerto Rico. Station locations are shown on a national scale (Figure 5a) and on a state-scale for California (Figure 5b).

The NSMN includes 840 accelerograph systems at 540 stations located in 33 states and the Caribbean (Table 6). Of the total number of accelerographs 750 are analog, 90 are digital, and 40 are multiple channel structural array systems. Of the 540 stations, $300(56 \%)$ are classified as free-field stations or buildings less than 2 stories, $160(30 \%)$ are classified as buildings of 2 stories or more, $70(13 \%)$ are associated with dams and $20(4 \%)$ are associated with bridges. 
The strong-motion stations comprising the NSMP as summarized in Table 6 and plotted in Figures 5a and $5 \mathrm{~b}$ are superimposed on maps showing average population exposure to $0.1 \mathrm{~g}$ (Borcherdt, et al., 1997). The overall spatial distribution of stations conforms quite well to the average annual population exposure to $0.1 \mathrm{~g}$ as inferred from the new seismic hazard maps (Frankel, et al., 1997). The maps show that the stations do indeed tend to be concentrated in areas for which the average annual population exposure is greatest.

The maps suggest some slight redistribution of stations may be appropriate, but such decisions can only be made once the individual locations and objectives are considered in detail. For example, some stations installed in cooperation with the $\mathrm{COE}$ are placed on dams consistent with objectives of that federal agency and would not be candidates for moving to an urbanized area. Strong motion stations near Mammoth Lakes and Eureka CA have been installed because of high seismicity and even though the population density is not as high as in some other areas, local concern with earthquakes may require that the stations not be redistributed. The maps clearly point out that stations are needed in a number of areas not yet instrumented including areas in New York City. The number of existing stations per $100 \mathrm{~km}^{2}$ is in most areas at least an order of magnitude less than that inferred as needed at the national workshop of the CASMP (Stepp, 1997).

Table 6. Statewide distribution of accelerographs associated with the National Strong-Motion Program of the U.S. Geological Survey *.

\begin{tabular}{llllll}
\hline State & Stations & $\begin{array}{l}\text { Accelero } \\
\text { graphs }\end{array}$ & State & Stations & $\begin{array}{l}\text { Accelero } \\
\text { graphs }\end{array}$ \\
\hline Alabama & 01 & 01 & New Mexico & 02 & 08 \\
Alaska & 47 & 56 & New York & 07 & 08 \\
Arizona & 04 & 05 & North Carolina & 02 & 02 \\
Arkansas & 06 & 07 & Ohio & 01 & 01 \\
California & 280 & 450 & Oklahoma & 01 & 01 \\
Colorado & 01 & 01 & Oregon & 19 & 77 \\
Georgia & 02 & 02 & Pennsylvania & 02 & 02 \\
Hawaii & 32 & 32 & Rhode Island & 01 & 01 \\
Idaho & 03 & 08 & South Carolina & 05 & 06 \\
Illinois & 03 & 03 & Tennessee & 07 & 09 \\
Indiana & 01 & 01 & Utah & 24 & 31 \\
Kansas & 01 & 01 & Vermont & 01 & 01 \\
Kentucky & 01 & 01 & Virginia & 02 & 02 \\
Massachusetts & 06 & 10 & West Virginia & 01 & 01 \\
Missouri & 15 & 21 & Washington & 22 & 43 \\
Montana & 05 & 08 & Puerto Rico & 17 & 22 \\
Nevada & 15 & 15 & Virgin Islands & 01 & 01 \\
New & 02 & 02 & & & \\
Hampshire & & & & 540 & 840. \\
\hline Total & & & & &
\end{tabular}

* Tri-axial accelerographs $=800($ Analog $=750 ;$ Digital $=90)$

Multi-channel structural arrays $=40$

Other devices (Seismic alarms, $\ldots=40$ ) 


\section{CURRENT SHORT-TERM PLANS}

Short-term plans of the NSMN, as specified in recent 5-year planning efforts (Porcella, pers. commun.), call for the replacement of analog instrumentation at 150-175 stations throughout the $U$. S. The present plan based on existing personnel resources includes upgrading 30 or more permanent stations per year to digital on-site recording (funds permitting). This effort includes analog recorders presently located at 7075 sites in southern Calif., 40-45 sites in northern and central Calif., 15-20 sites in the Pacific Northwest, 10-15 sites in Alaska, and 15-20 sites in other key seismic regions of the United States. The needed NSMN station upgrades to digital technology will permit improvements in dynamic range by about $90 \mathrm{~dB}$, signal resolution by as much as about $60 \mathrm{~dB}$, inclusion of absolute timing with GPS receivers, digital data storage with 20 megabyte capacity on digital memory cards, and real and near-real time data transmission and instrument communication capabilities. Implementation of upgrades is intended for both structureresponse and ground-motion monitoring purposes.

\section{THE NATIONAL STRONG-MOTION DATA CENTER (NSMDC)}

The National Strong-Motion Data Center (NSMDC) is responsible for the digitization, processing, archival, and dissemination of data collected on the cooperative National Strong-Motion Network. The center has responsibility for the development and maintenance of guidelines and standards for digitization, processing and archival of strong-motion data. The center helps maintain the NSMP www site with Internet access to processed data acquired on the network.

Future short-term plans call for expansion of near-real time data retrieval and dissemination capabilities (funding and personnel resources permitting). It is intended that approximately 175 near-real time stations will become operational at locations throughout the United States using standard telephone communication. This capability will permit near-real time earthquake monitoring, rapid assessments of strong shaking for emergency response purposes, near-real time warnings for some areas, and significantly improved data dissemination capabilities.

It is envisioned that the NSMDC, through the WWW, should become a hub of information about the availability of strong-motion data not only from the NSMP, but other online regional, state, local, and international data centers, with access to other resource centers provided via links through the Internet. The NSMDC WWW site should serve as an interface to a searchable database that includes time series (acceleration, velocity, and displacement), spectral and response data, with dynamic display capabilites for previewing these data, as well as detailed information about station locations, instrumentation, and geotechnical or structural properties.

\section{DATA UTILIZATION}

The NSMP maintains a basic strong-motion data interpretation capability focused on the measurement and prediction of strong ground motion and structural response in densely urbanized areas with high seismic risk. This basic data utilization effort, conducted in support of the national strong-motion network, addresses issues pertaining to the radiation and attenuation of strong-ground motion, the amplification and damping effects of local soil deposits, soil-structure interaction effects, structural response, and implications of these results for purposes of code improvements. Results of these efforts help provide guidelines for design, installation, and maintenance of instrumentation to record future events.

\section{STRONG GROUND-MOTION MEASUREMENT NEEDS FOR EARLY WARNING}

Most earthquake damage is the result of seismic waves that travel from the fault and shake the earth. The first energy to arrive is in the form of P-waves, which travel at typical velocities of $5-6 \mathrm{~km} / \mathrm{s}$, but the more damaging, larger amplitude S-waves travel at almost half the speed of the P-waves. Because seismic data can be continuousiy telemetered to a central network site at the speed of light (that is, nearly instantaneousiy 
compared to the speed that seismic waves travel through the earth), it is possible for seismic networks to provide advance warning of the imminent arrival of strong ground motion at distances beyond where the first seismometers detect the quake. Computer programs that continuously analyze the telemetered data could identify when a large earthquake is occurring and issue a brief radio broadcast of the magnitude and location of the earthquake (Heaton, 1985; Holden et al., 1989; National Research Council, 1991). Depending on the location of the recipient of the warning and type of facility to be affected, end-users could take appropriate action. For example, early warning broadcasts could warn people in poorly designed structures, protect equipment such as electrical power substations, stop trains and automotive traffic. Communications equipment could momentarily be halted to prevent damage during the earthquake and ensure that power and communication systems are intact for subsequent rescue operations. Fire station garage doors could automatically be opened so that fire-fighting vehicle would not be trapped if the building were to shift.

The length of the advance warning increases with the distance between the quake and the recipient of the warning, but the shaking generally attenuates with increasing epicentral distance. However, there are often critical damage zones well away from the fault. For instance, the 1989 Loma Prieta earthquake created significant damage and mortality in the San Francisco Marina district and at the Cypress freeway structure in Oakland. These areas were $90-100 \mathrm{~km}$ from the earthquake and could have been given only 8 seconds warning in advance of the $P$ wave arrival, but as much as 19 seconds warning in advance of the arrival of the damaging S-wave.

Even more elaborate warning systems are possible. Consider, for example, the operators in a control room of a public utility or railroad. Upon receiving the above "early warning", they must make rapid decisions about the continued operation of power plants or rail systems. Seismic networks could transmit via dedicated communication channels to these clients the 1-second average of ground motion amplitude at each station of the seismic network for local generation of a shaking map. This map would provide visual confirmation of an alert message, since the operator would observe the wave front propagate across the network at speeds of $5-8 \mathrm{~km} / \mathrm{s}$. For example, it would take more than 60 seconds for the energy to propagate from a large quake in the San Francisco bay region to the Oregon border, and nearly 90 seconds for energy for a Parkfield event to reach the border.

Early warning of strong ground motion and the above wave front expansion display require 1) a network of sensors (accelerometers) sited along active faults that records the ground motion with high fidelity, 2) telemetry that transmits with minimal delay the full dynamic range of these signals back to a central network site, 3) real-time software at the central site that reports on significant earthquakes during rupture, and 4) a dedicated broadcast system to distribute this information to the public.

\section{GROUND-MOTION MEASUREMENT NEEDS FOR MAPS OF SHAKING}

After an earthquake the ability to rapidly deploy rescue equipment can save not only lives but also property. Accurate rapid deployment is currently hindered because it is difficult for a centralized command center to compile damage reports from a wide region. This occurs because citizens frequently cannot report damage and fires due to overloaded telephone systems; consequently, the initial damage reports are often distributed via radio and television broadcasts. This information may misrepresent the full scale of the crisis, because local site conditions influence the amplitude of earthquake ground motion, the population distribution governs the location where ground motion is reported, and communications can be disrupted in the epicentral region. A notable example occurred for the 1989 Loma Prieta earthquake. Aerial television coverage of the World Series being played at Candlestick Park south of San Francisco immediately diverted from the stadium to the sites of earthquake damage in San Francisco and Oakland. However, the earthquake occurred $100 \mathrm{~km}$ to the southeast in the Santa Cruz Mountains and the heavily damaged cities of Watsonville and Santa Cruz close to the epicenter received comparatively little media attention for several days.

Within minutes after a large earthquake, emergency services coordinators could have access to automatically generated maps that show observed shaking intensity and predicted damage patterns. This 
information can be used to efficiently deploy fire fighting, rescue, and medical services. Seismic networks provide the basic parameters needed to predict the ground motion throughout the affected region, namely, hypo-central coordinates, earthquake magnitude, mechanism, and rupture zone extent (from aftershock locations). Preliminary information on location and magnitude can be available within seconds of occurrence, refined estimates of magnitude and mechanism within 3-10 minutes, and the extent of the aftershock zone imaged by aftershock locations within 30-60 minutes.

Observations from strong-motion instrumentation can be integrated into the maps of predicted ground shaking. Various estimates of ground motion, such as peak ground acceleration, velocity, shaking duration, energy content, or spectral values can be calculated in real-time. By combining this observed data with the predicted ground motions, it would be possible to immediately see where strong ground motion occurred, and to assess the reliability of the forecast model of ground shaking.

\section{MEASUREMENT NEEDS FOR STRUCTURAL ENGINEERING RESEARCH}

Evolution of new technologies in earthquake resistant design, construction and retrofit practices requires systematic and efficient verification of the performance of structures built or strengthened with the new technologies. Such verification can only be accomplished by strategically deploying seismic sensors in such structures to record their performances during future events. The severity of damages to numerous steel structures during the January 17, 1994 Northridge earthquake (Ms 6.7) and Kobe (Japan) earthquake of January 17, 1995 (Ms 6.8) argues strongly for instrumentation of both the new and retrofitted structures. Seismic performance data from future events is essential to assess the effectiveness and revise and/or improve design, construction and retrofitting practice.

There are many facets of response of structural systems that are not well understood. In many cases, although theoretical solutions abound, actual response data is scarce or non-existent. One important aspect of structural response is the soil-structure interaction. In many cases, under a specific geotechnical environment, certain structures will respond differently than if that structure was built as a fixed based structure on a very stiff (e.g., rock) site condition. This alteration of vibration characteristics of structures due to soil-structure interaction (SSI) can be both beneficial and detrimental for their performances. To date, a community consensus on the role of SSI does not exist. In Mexico City, during the Michoacan earthquake of Sept. 19, 1985, many structures were negatively affected due to SSI, because the lengthening of their fundamental periods placed them in a resonating environment close to the approximately 2 second period of Mexico City lakebed. However, under different circumstances, SSI may be beneficial because it produces an environment whereby the structure escapes the severity of the response spectra due to shifting of its fundamental frequency. Certainly, in a basin such as that of Los Angeles area, SSI may cause both beneficial and detrimental effects in the response of structures. The identification of the circumstances under which SSI is beneficial or detrimental and the parameters is a necessity (Celebi and Nishenko, 1997).

Until resources can be identified and implemented to fill the long-term national needs, short-term structural instrumentation needs are:

1. Pursue an aggressive program to develop resources to instrument man-made structures in cooperative partnerships with other agencies at a spatial density suggested by national and regional estimates shown in Figures 2 and 5. A minimal short-term instrumentation plan for structures with annual population exposure to $0.1 \mathrm{~g}$ exceeding 1500 (see Figures $5 \mathrm{a}$ and $5 \mathrm{~b}$ ) should include:

a) One $\%$ of federally owned and leased buildings that are higher than 3 stories,

b) One $\%$ of all buildings $>3$ stories not instrumented by other programs, 
c) All new or retrofitted buildings that incorporate significant new technologies such as base-isolation, viscous elastic dampers, recently developed and untested methods of design and construction,

d) Most or all significant lifelines in urban environments, that are not instrumented by other programs,

e) For those areas within $10 \mathrm{~km}$ of faults with potential $\mathrm{Mw}>7.0$ events $5 \%$ of all buildings taller than 3 stories or single or double story buildings if not regular structures (e.g. tilt-up buildings, pre-cast buildings etc) and $50 \%$ of all lifelines should be instrumented.

f) Special areas with high population exposure (a) In San Francisco Bay Area (such as Lower Market Area in San Francisco, Emeryville, Marina District in San Francisco, South SF Peninsula, Oakland), (b) In LA Area (such as Sherman Oaks, Van Nuys, Downtown LA, Santa Monica, San Bernardino), (c ) In Pacific Northwest (Seattle, Portland), (d) in Central and Eastern US (Memphis [Tn], Cape Girardeau [MO], Charleston [SC] and others) that are vulnerable should have special structural instrumentation plans developed to reflect the risk associated with their specific seismic sources and site effects.

g) Special purpose experiments to solve critical research issues such as (a) soil-structure interaction and (b) topographical response should be implemented. 


\section{REFERENCES}

Borcherdt, R.D., and Matthiesen, R.B., 1980, U.S. strong-motion programs: Seventh World Conf. on Earthquake Engineering, Proc. 7, 2, 9-16.

Borcherdt, R.D., Anderson, J.G., Crouse, C.B., Donovan, N.C., McEvilly, T.V., and Shakal, T.F., 1984, National planning considerations for the acquisition of strong ground-motion data: Earthquake Engineering Research Institute Special Publ. 84-08, 57 p.

Borcherdt, R.D., 1994, Estimates of site-dependent response spectra for design (methodology and justification), Earthquake Spectra, 10, pp 617-653.

Borcherdt, R.D., and Frankel, A., 1997, Recommendations for EHRP 5-Year Plan, U. S. Geological Survey Open-File Report No. 97-58, 47 pp.

Borcherdt, R.D., 1997, US National Strong Motion Program, Proceedings, Vision 2005: An Action Plan for Strong-motion Programs to Mitigate Earthquake Losses in Urbanized Areas, National Science Foundation, Monterey, CA, April 1997.

Borcherdt, R.D., Frankel, A., Joyner, W.B., and Bouabid, J., 1997, Vision 2005 for earthquake groundmotion measurement in the United States, Proceedings, Vision 2005: An Action Plan for Strongmotion Programs to Mitigate Earthquake Losses in Urbanized Areas, National Science Foundation, Monterey, CA, April, 1997.

Higgens, C.J. (ed), 1993, Proceedings, Workshop on Research Needs for Strong-Motion Data to Support Earthquake Engineering, Albuquerque, NM.

Iwan, W.D.(ed.), 1978, Strong motion earthquake measurement arrays, Proceedings, International Workshop on Strong-Motion Earthquake Instrument Arrays, Honolulu, Hawaii.

Iwan, W.D.(ed.), 1981, US Strong motion earthquake instrumentation, Proceedings, US National Workshop on Strong-Motion Earthquake Instrumentation, Santa Barbara.

Matthiesen, R.B., 1978, On the development of strong-motion instrument networks in the United States, US Geol. Survey Open-file Rept., 78-1024.

National Research Council, 1980, US Earthquake Observatories: Recommendations for a New National Network, National Academy Press, Washington, D.C.

NSF/USGS, 1976, Earthquake Prediction and Hazard Mitigation Options for USGS and NSF Programs, National Science Foundation Publication NSF 76-49, "Newmark-Stever Report".

Nigbor, R.L., 1997, Present and future needs for strong-motion information, Proceedings, Vision 2005: An Action Plan for Strong-motion Programs to Mitigate Earthquake Losses in Urbanized Areas, National Science Foundation, Monterey, CA, April 1997.

Spudich, P., Boore, D.M., Borcherdt, R.D., Brady, A.G., Celebi, M., Fletcher, J.B., Holzer, T., Joyner, W.B., Safak, E., and Youd, T.L., 1985, National plan to record earthquake motions on the ground and in man-made structures: U.S. Geological Survey Report.

Stepp, C.J., 1997, Proceedings, Vision 2005: An Action Plan for Strong-motion Programs to Mitigate Earthquake Losses in Urbanized Areas, National Science Foundation, Monterey, CA, April 1997. 


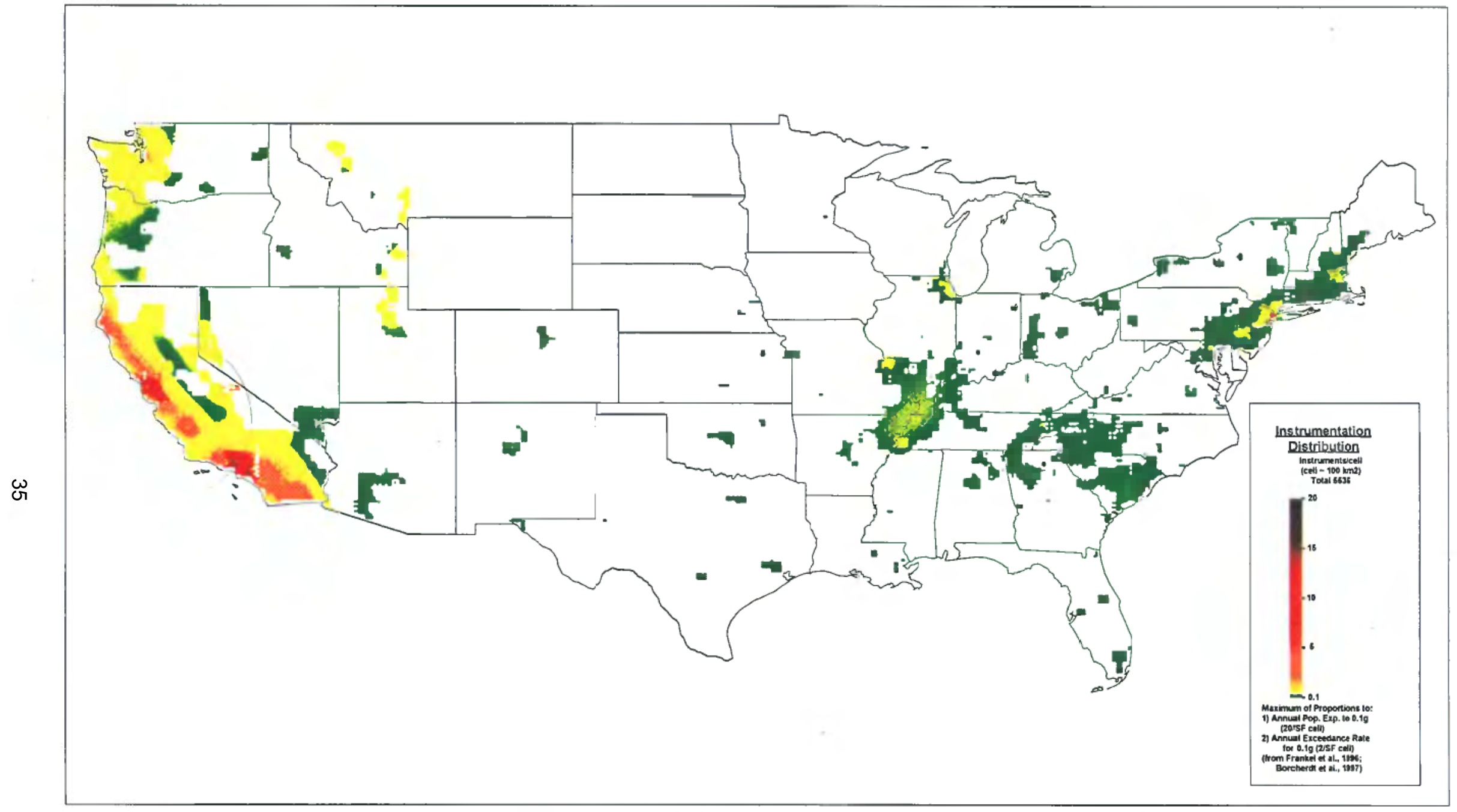

Figure 1 Preliminary estimate of strong-motion instrumentation needed to record the next large earthquake at sites of most significance for public safety. (Estimate based on the annual exceedance rate for $0.1 \mathrm{~g}$ and population exposure). 


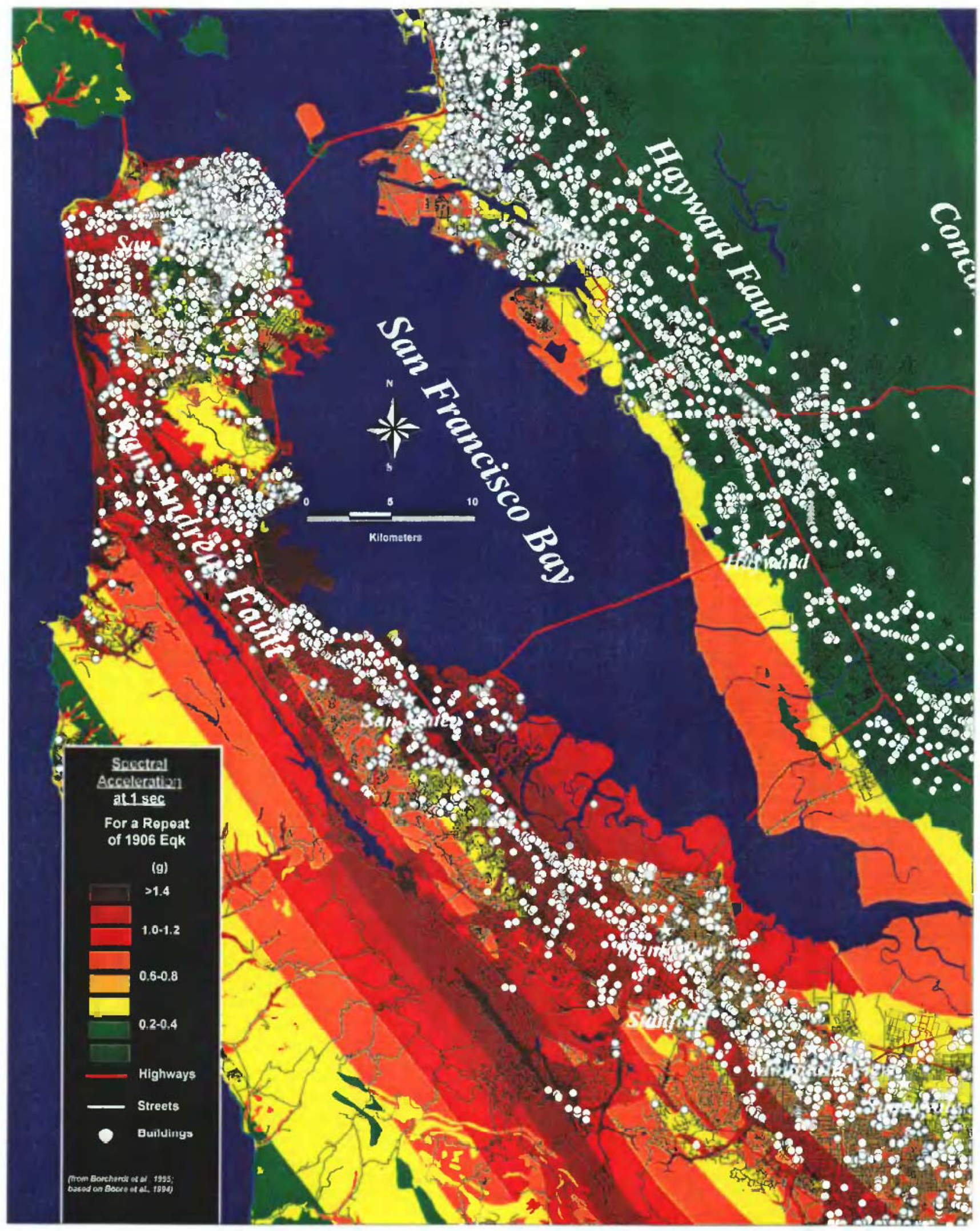

Figure 2a. Spectral acceleration levels at 1.0 second period expected for major building locations in the southern San Francisco Bay region for a repeat of the 1906 earthquake $(\mathrm{Mw}=7.7)$. 


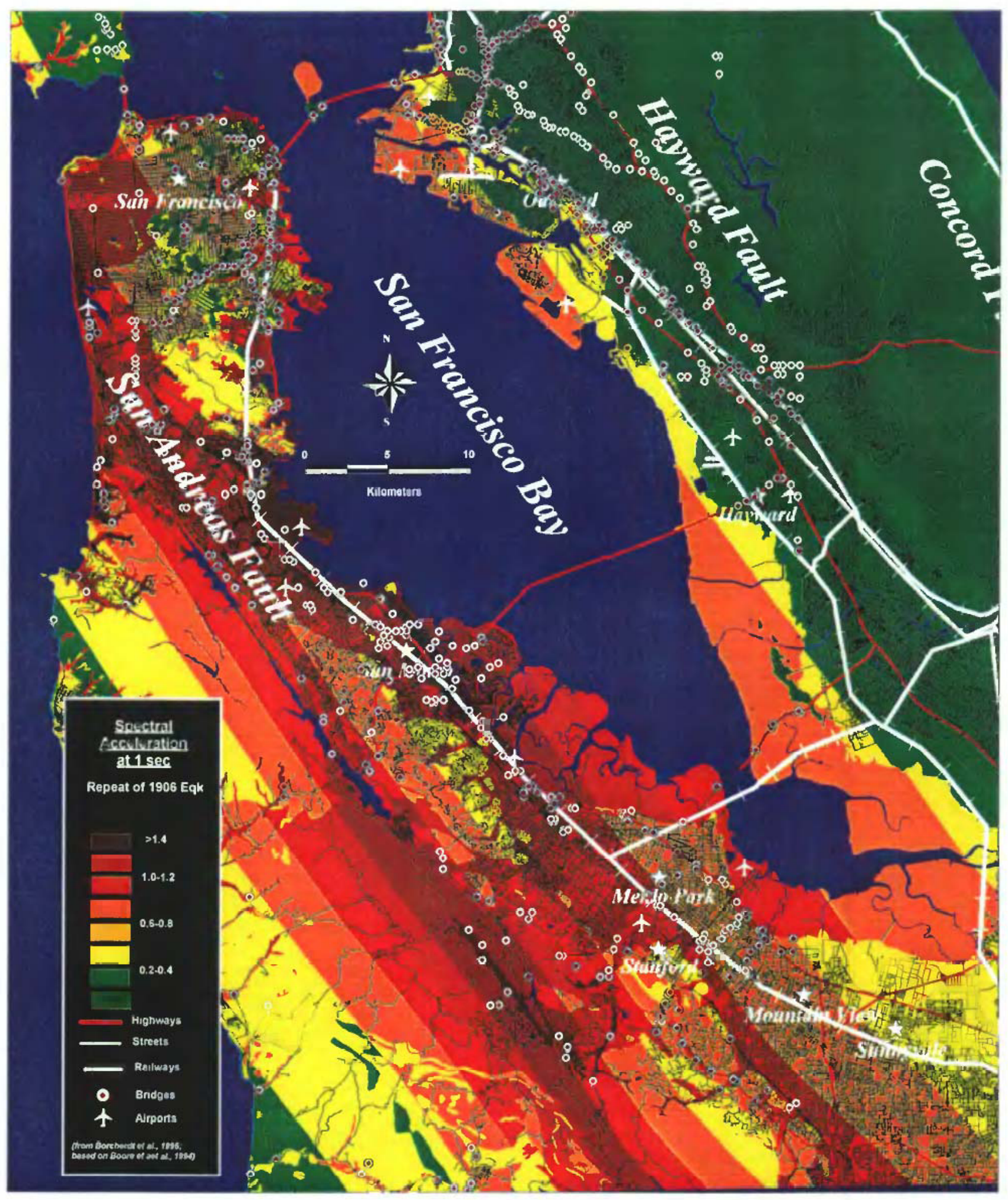

Figure 2b. Spectral acceleration levels at 1.0 second period expected for major transportation facilities (Highways, streets, bridges, railways, and airports) in the southern San Francisco Bay region for a repeat of the 1906 earthquake $(\mathrm{Mw}=7.7)$. 


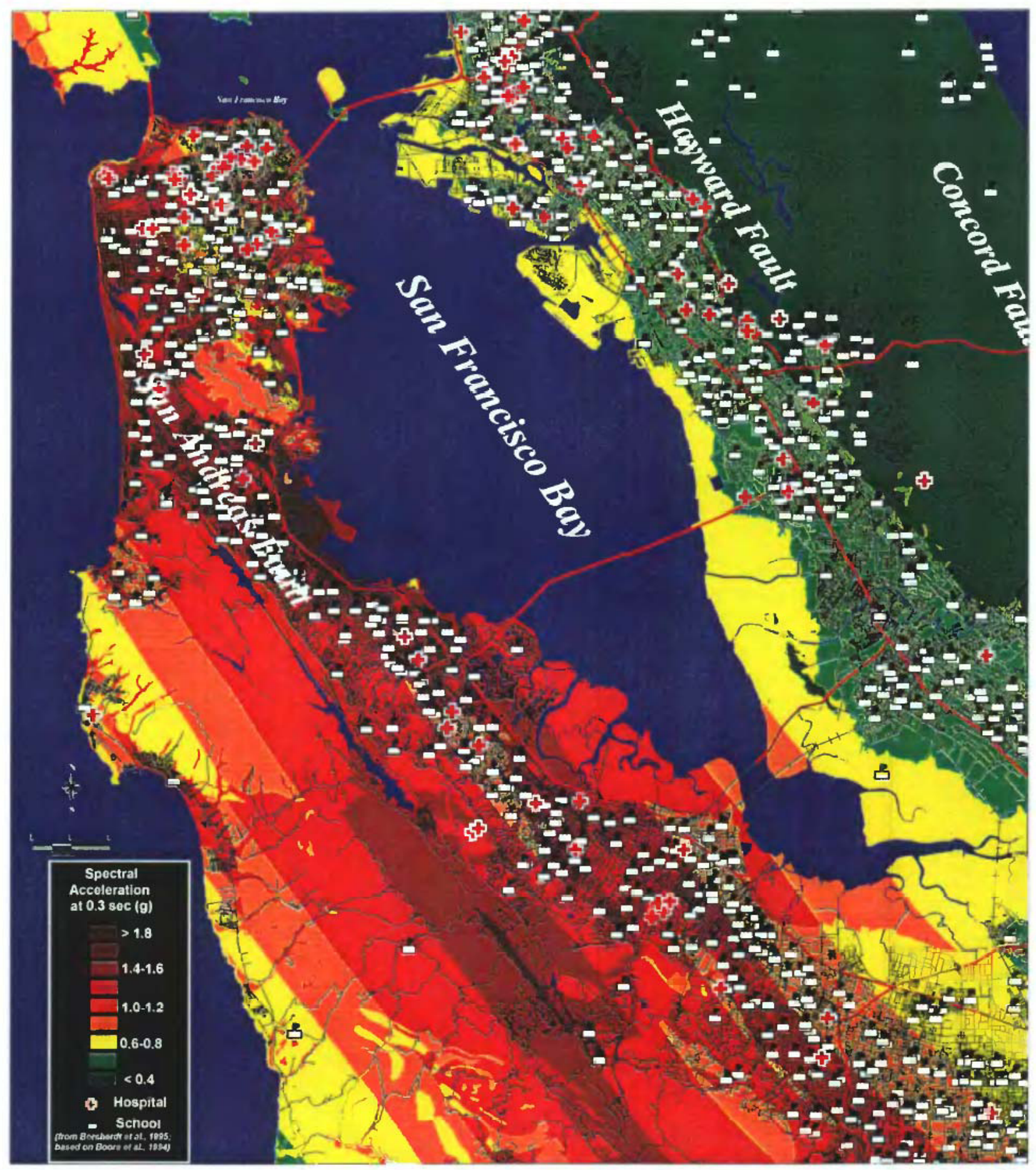

Figure 2c. Spectral acceleration levels at 0.3 second period expected for schools and hospitals in the southern San Francisco Bay region for a repeat of the 1906 earthquake $(\mathrm{Mw}=7.7)$. 


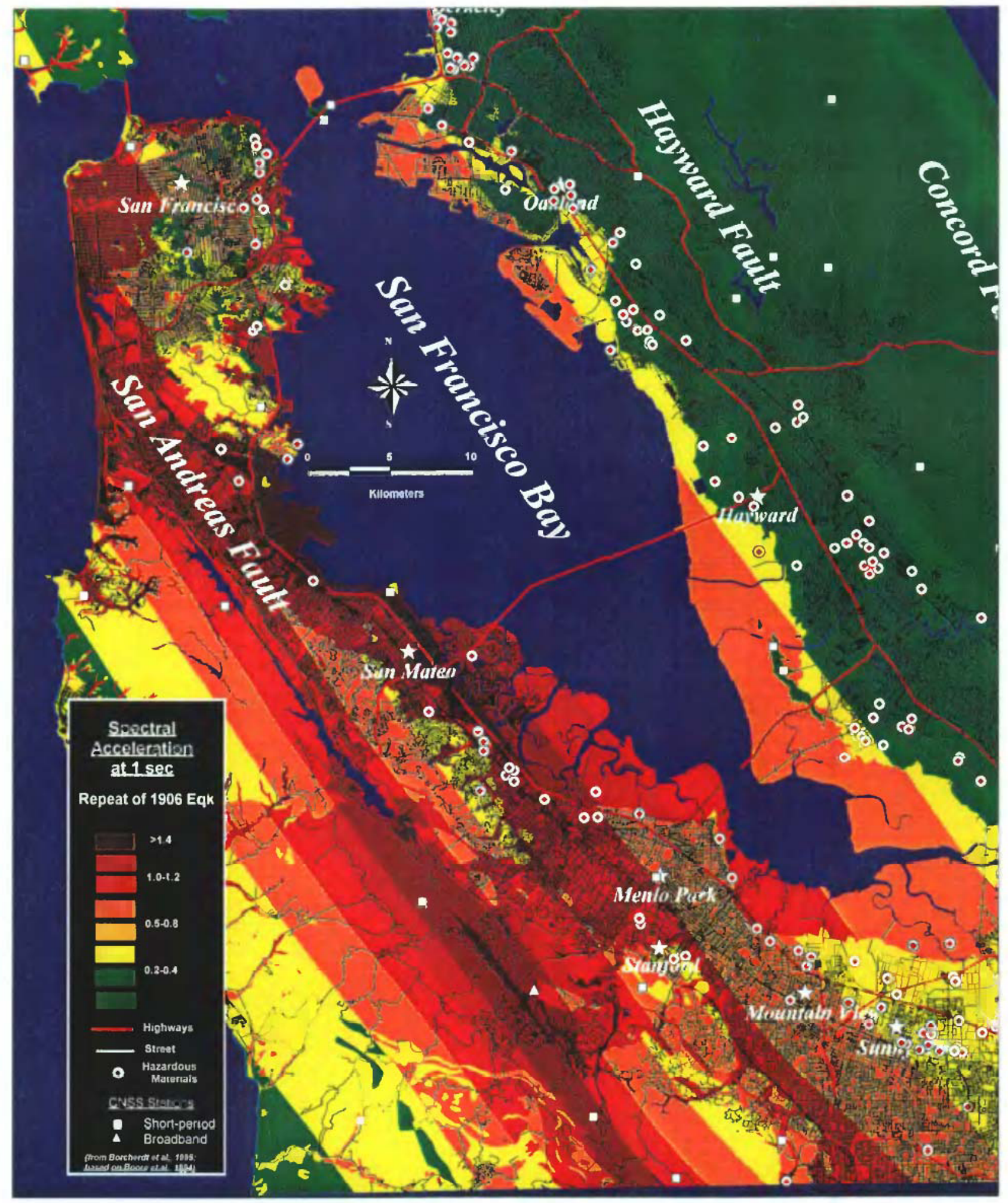

Figure 2d. Spectral acceleration levels at 1.0 second period expected for hazardous material sites in the southern San Francisco Bay region for a repeat of the 1906 earthquake $(\mathrm{Mw}=7.7)$. Locations of short-period and broadband CNSS stations are shown. 


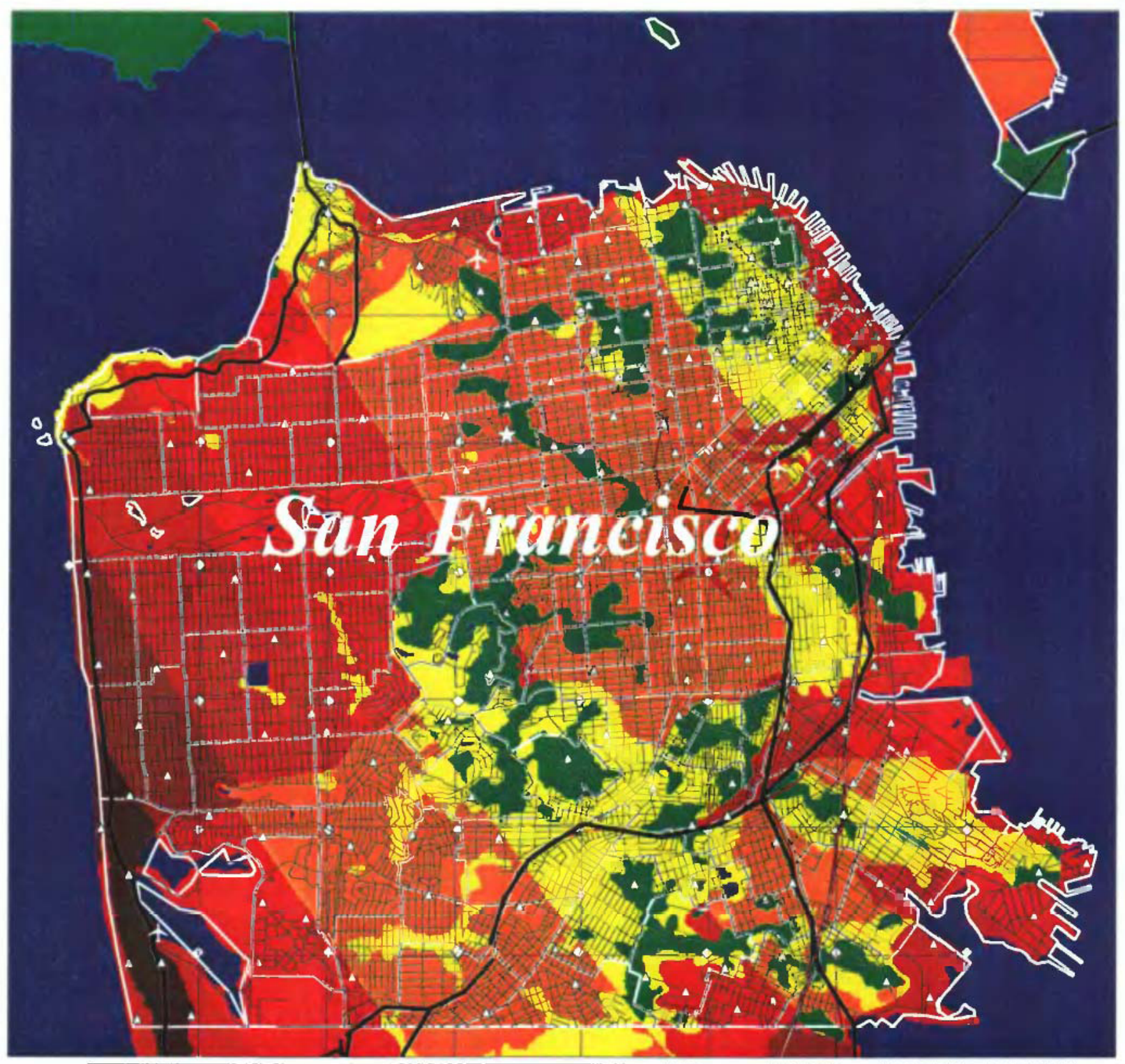

Ground-Motion Measurement for Public Safety (Grid 35 Sm .Sta./100 km2)

Sa 1.0 sec Mw = 7.7 (1906); Census tracts (149), white; Str.mot. sta. $(\sim 42+\sim 181)$, triangle

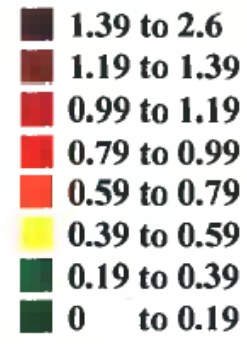

Figure 3a Map showing strong-motion station distribution required to thoruoghly measure ground shaking variations for public safety for a repeat of the 1906 earthquake (Mw 7.7). 


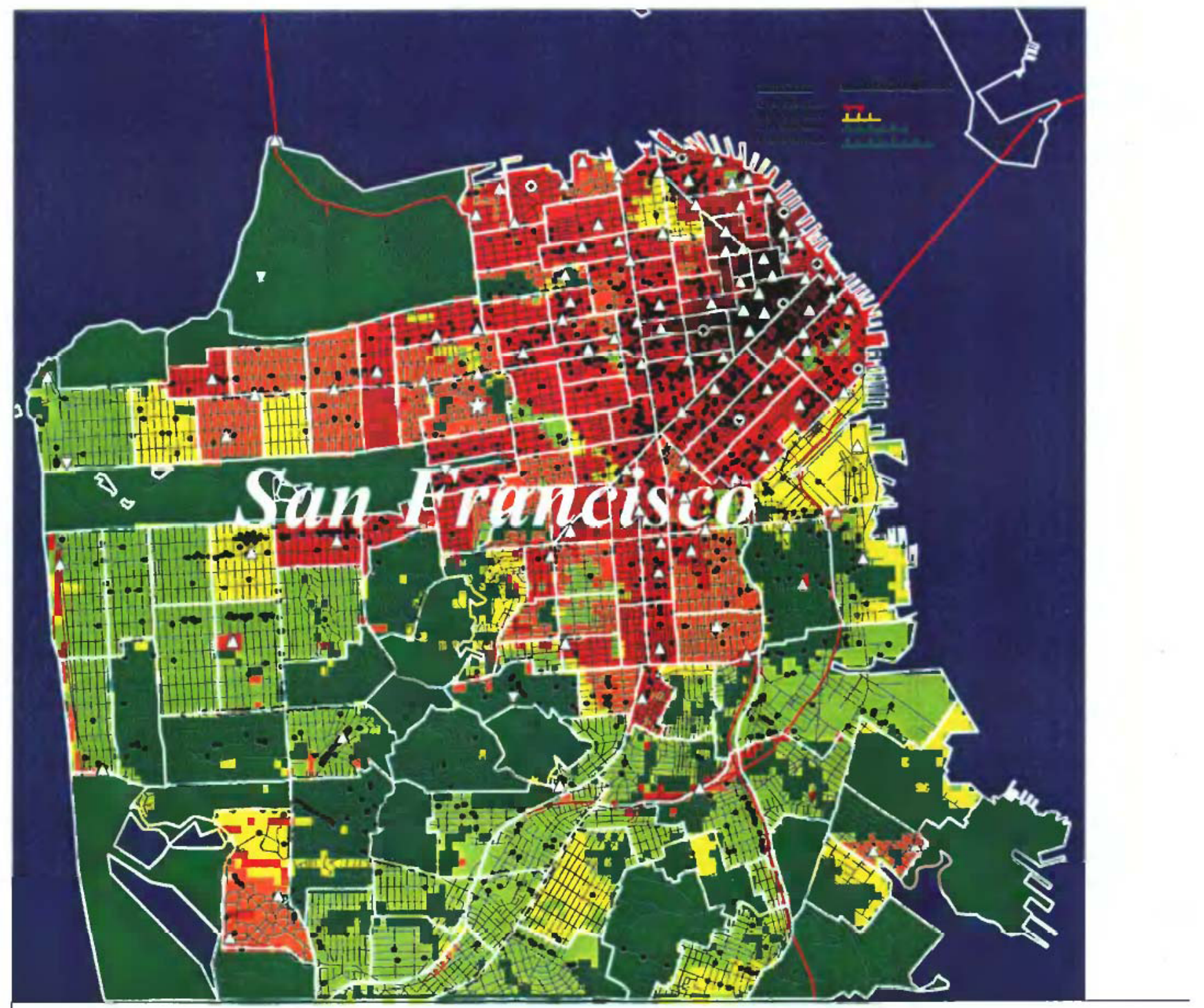

Ground-Motion Measurement for Public Safety

Res_Loss+Corn_Loss for Mw 7.7 (1906); Cerisus Trucls (149), while; Bldgs. bik.duls; SM Slus.(117), white dots; Boreholes(8), cir. dot

$\begin{array}{rr}6,600 \text { to } 16,500 \\ 3,000 \text { to } & 6,600 \\ 1,800 \text { to } & 3,000 \\ 1,200 \text { to } & 1,800 \\ 800 \text { to } & 1,200 \\ 500 \text { to } & 800 \\ 400 \text { to } & 500 \\ 300 \text { to } & 400 \\ 200 \text { to } & 300 \\ 0 \text { to } & 200\end{array}$

Figure 3b. Map showing expected residential and commercial losses in San Francisco for a repeat of the 1906 earthquake and station distribution necessary to measure ground shaking for public safety in blocks with losses > \$1 million. 


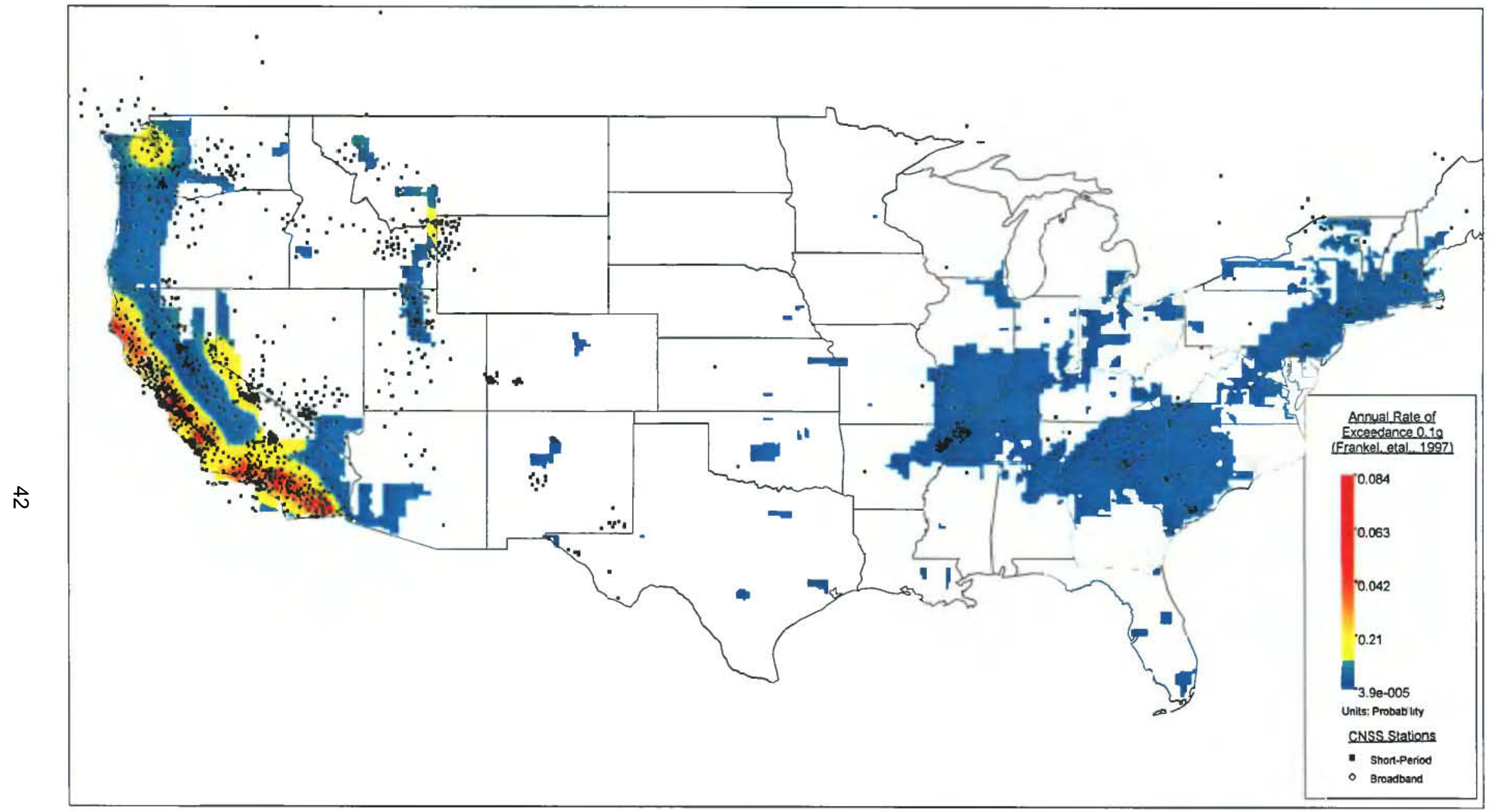

Figure 4a Annual rate of exceedance for $0.1 \mathrm{~g}$ (from Frankel et al., 1996) and locations for short-period and broadband seismic stations as compiled for CNSS (Malone, pers. commun. 1997). 


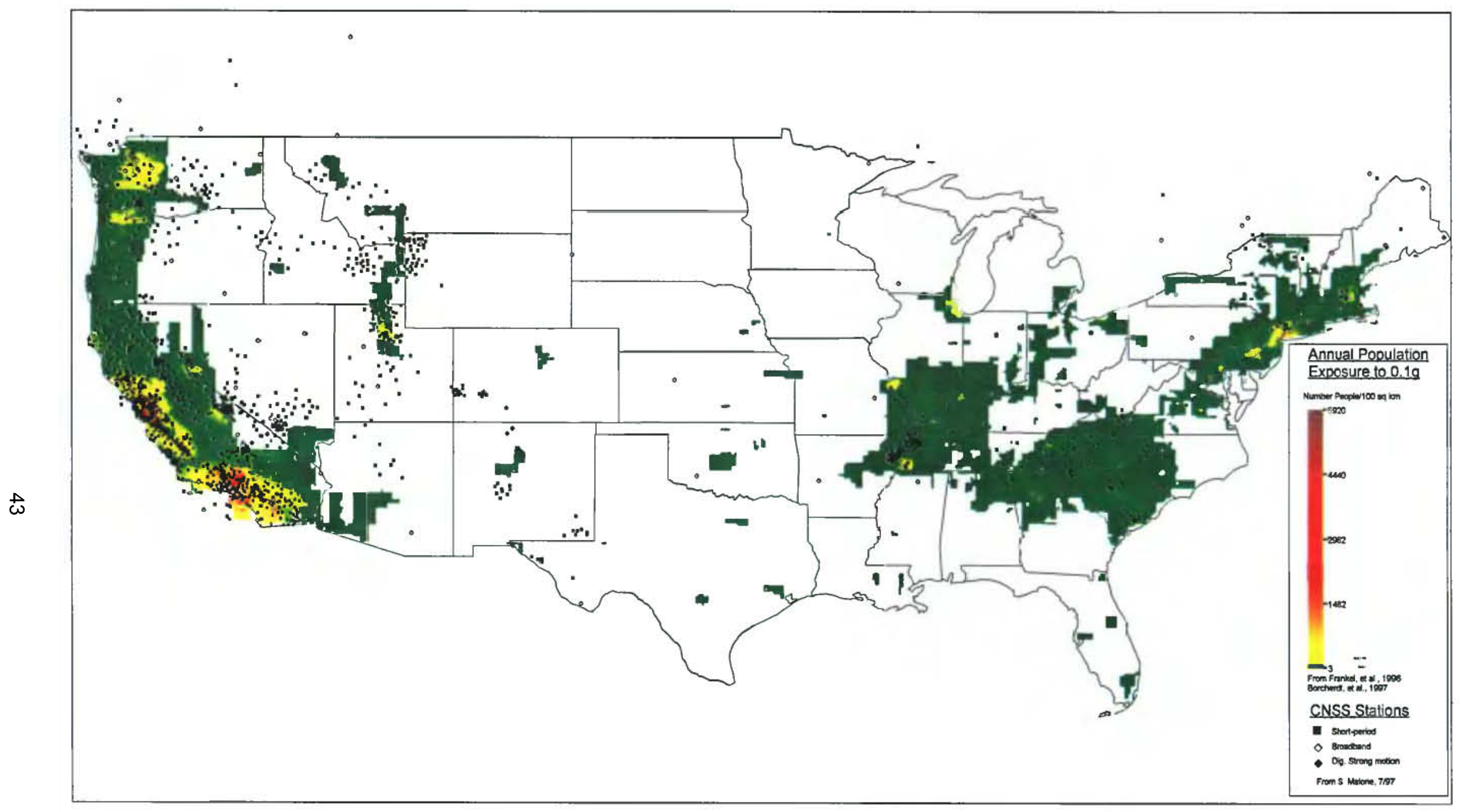

Figure 4b Locations of CNSS stations superimposed on the average annual population exposure for 0.1g exceedance level (Frankel, et al., 1996; Borcherdt, et al., 1997). 


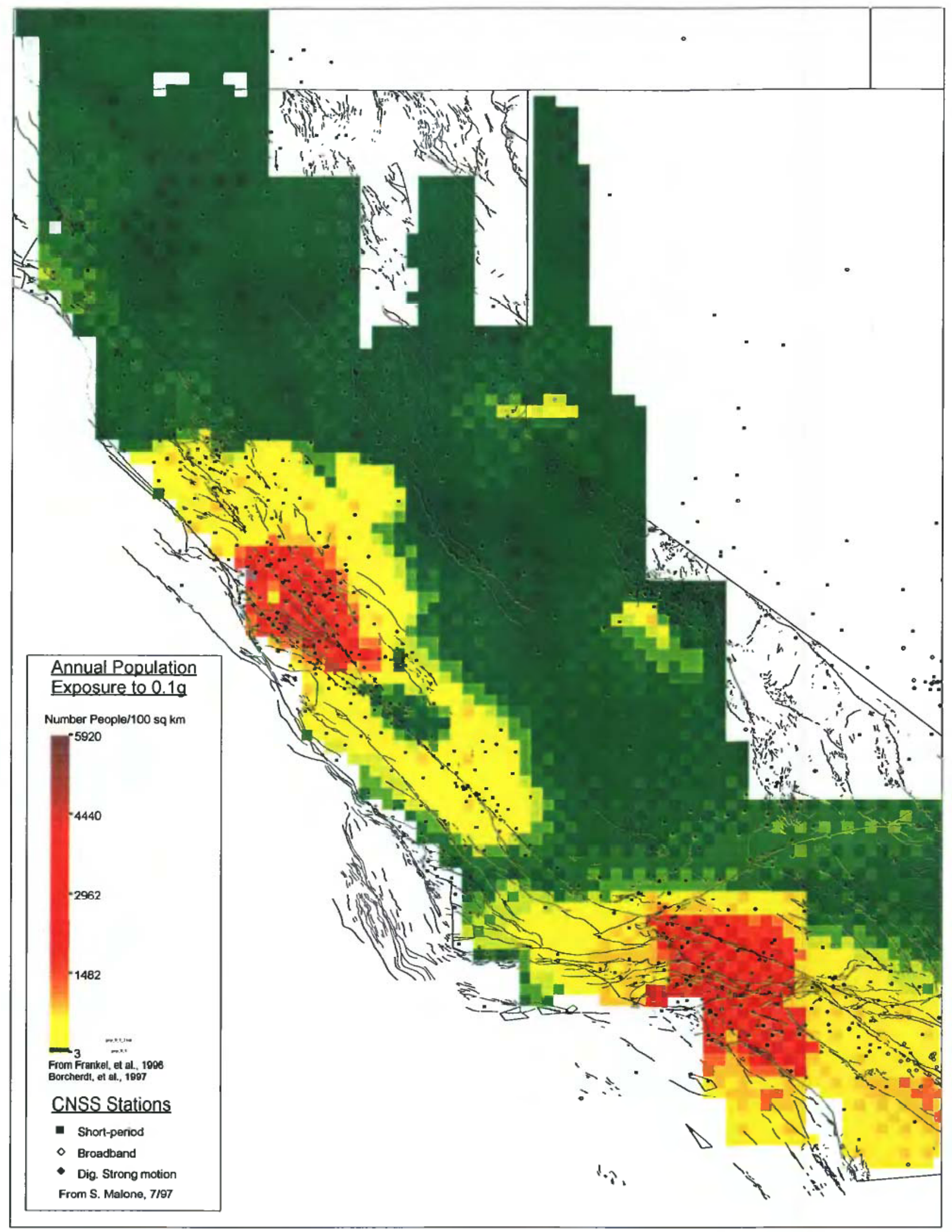

Figure 4c Locations of CNSS stations superimposed on the average annual population exposure for $0.1 \mathrm{~g}$ exceedance level (Frankel, et al., 1996; Borcherdt, et al., 1997) and fault map. 


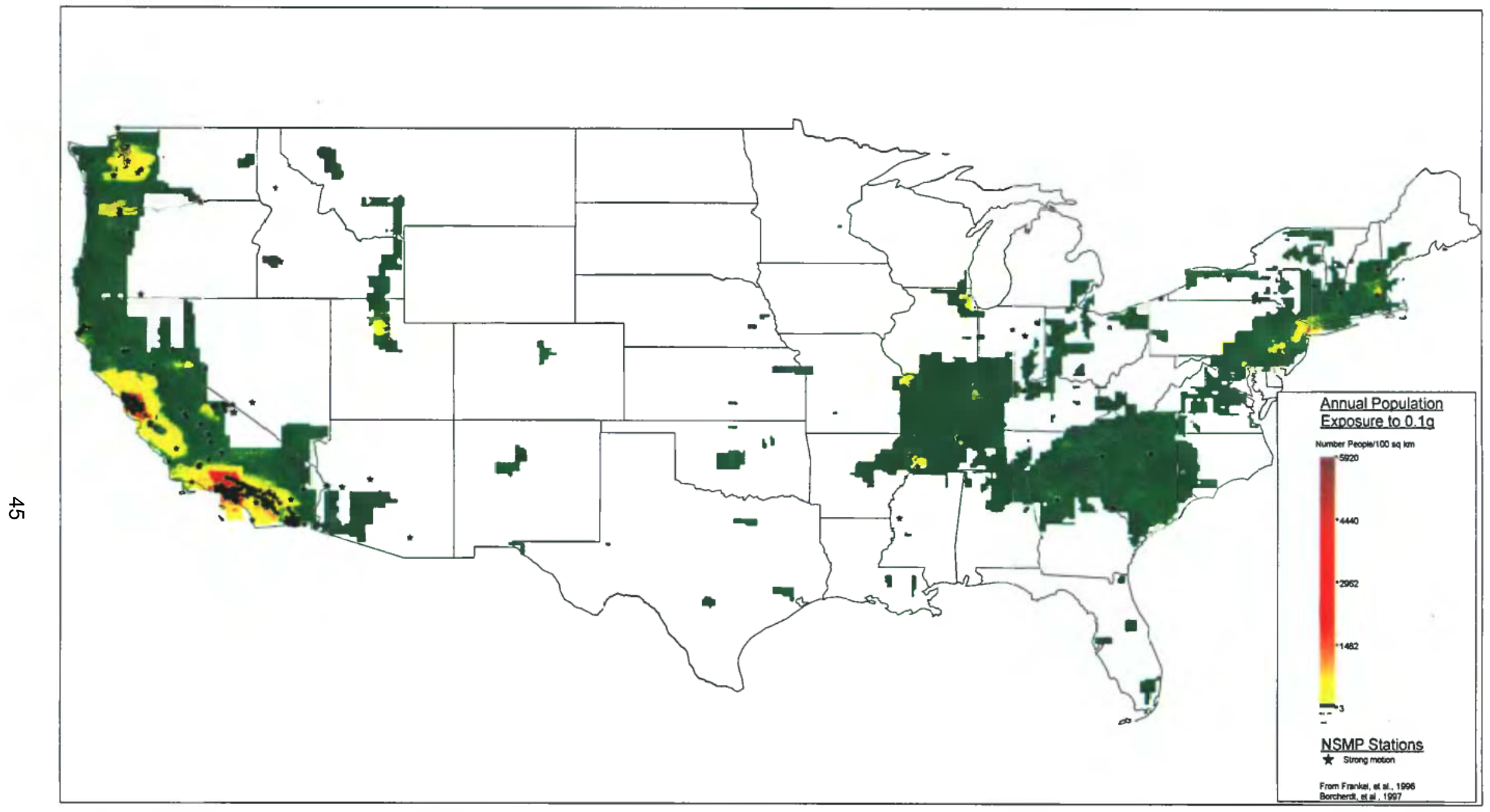

Figure 5a Strong-motion stations comprising the NSMP superimposed on the average annual population exposure for 0.1g exceedance level (Frankel, et al., 1996; Borcherdt, et al., 1997). 


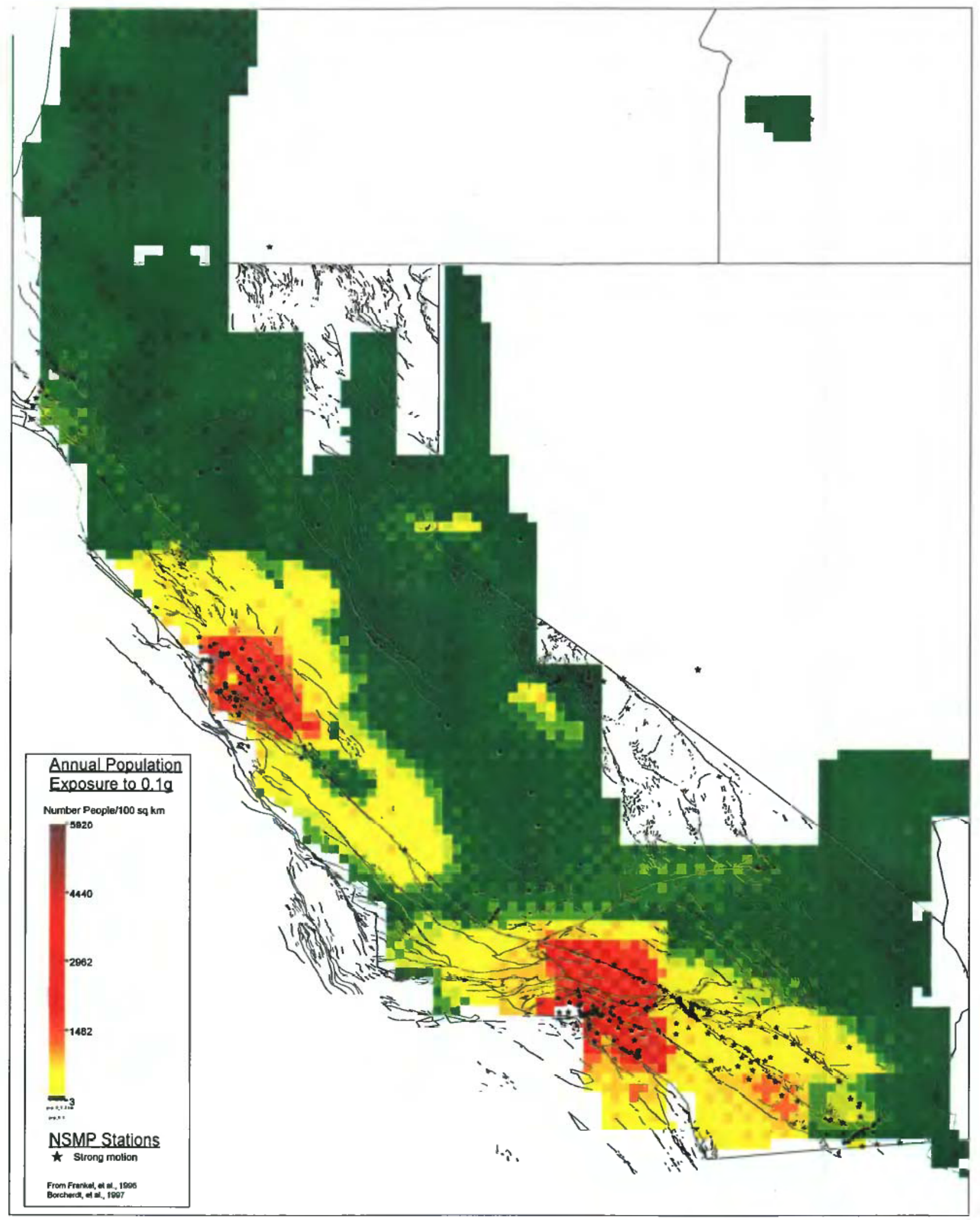

Figure 5b Strong-motion stations comprising the NSMP superimposed on the average annual population exposure for 0.1g exceedance level (Frankel, et al., 1996; Borcherdt, et al., 1997) and mapped faults. 